\title{
Acuerdos comerciales entre corsarios y españoles en el Golfo-Caribe, siglo XVI
}

\section{Trade Agreements between Privateers and Spanish Traders in the Gulf-Caribbean in the 16th Century}

\author{
RODRIGO DE LA O / rodrigodelao.historiador@gmail.com \\ CIESAS-Peninsular
}

\section{Resumen / ABstract}

El propósito de este artículo es reconstruir los procesos de negociación para el intercambio comercial celebrado entre corsarios ingleses y franceses con colonos españoles en el Golfo de México y el Caribe durante el siglo XVI. Se analizan tres casos obtenidos del Archivo General de Indias a través del Portal de Archivos Españoles en Red. El análisis se enfocó en los principales actores sociales involucrados en los tratos y contratos, para observar cómo se desarrollaron las negociaciones entre las partes y las particularidades de cada caso. De esta manera, se establece un esquema general respecto al procedimiento de las negociaciones entabladas entre corsarios y españoles, y se concluye que el fenómeno de la piratería tuvo en el ámbito mercantil una vía para incorporarse a la vida de la región.

\section{Palabras Clave}

Autoridades hispanas, corsarios, intercambio comercial, negociaciones.
This paper studies the trade negotiations on commercial exchange held between English and French privateers and Spanish settlers for the Gulf of Mexico and the Caribbean Sea during the 16th Century. Three cases taken from the General Archive of the Indies (using the Portal of Online Spanish Archives) are analysed, focussing on the social actors engaged in the deals and contracts, so as to observe how the negotiations took place and the details involved. A general overview obtained of the negotiating procedures between the privateers and the Spanish settlers leads to the conclusion that for the phenomena of piracy, the commercial sector offered a way into the economic activity of the region.

\section{KEYWORDS}

Spanish Authorities, Privateers, Commercial Exchange, Negotiations.

RECIBIDO: 19/12/14 · ACEPTADO: 13/04/15

Revista MEXICANA DEL CARIBE, ISSN: 2448-7163

NuEVA ÉPOCA, NúM. 21, enero-junio 2016, pp. 42-89

DOI: 10.22403/UQROOMX/RMC21/02 


\title{
Accords et désaccords commerciaux. Corsaires et Espagnols dans le Golfe du Mexique-Caraïbe, XVlème siècle
}

\author{
Handelsovereenkomsten en handelsgeschillen \\ Piraten en Spanjaarden in de Golf van Mexico-Cariben
}

RODRIGO DE LA O / rodrigodelao.historiador@gmail.com

CIESAS-Peninsular

\section{Résumé / SAMENVATting}

L'objectif de cet article est de reconstruire les processus de négociations commerciales entre corsaires anglais et français d'une part, colons espagnols d'autre part, dans le Golfe du Mexique et la Caraïbe durant le XVlème siècle. Trois cas sont analysés, à partir des Archives Générales des Indes, par l'intermédiaire du Portail des Archives Espagnoles en ligne (Portal de Archivos Españoles en Red). L'analyse est centrée sur les principaux acteurs sociaux impliqués dans les traités et contrats, afin d'observer comment se développent les négociations entre les parties et les spécificités de chaque cas. De cette façon, un schéma général du processus de négociations entre corsaires et Espagnols est établi. Le texte conclut que le phénomène de la piraterie a connu, au niveau marchand, une forme d'incorporation à la vie régionale.
Het doel van dit artikel is om de onderhandelingsprocessen te reconstrueren die plaatsvonden in de commerciële interacties tussen Engelse en Franse piraten met de Spaanse kolonisten in de Golf van Mexico en de Cariben gedurende de zestiende eeuw. Drie casussen worden geanalyseerd die komen uit het Archivo General de las Indias via de portal van Archivos Españoles en Red (op het web). De analyse wordt toegespitst op de sociale protagonisten betrokken bij de handel en handelsovereenkomsten, om te bekijken hoe de onderhandelingen tussen de partijen zich ontwikkelden, met oog voor de bijzonderheden eigen aan elke casus. Op deze manier kan een algemeen schema uitgewerkt worden van de procedures van de onderhandelingen tussen piraten en Spanjaarden. Vastgesteld wordt dat het verschijnsel van de piraterij via de handel deel kon gaan uitmaken van het dagelijks leven in dit gebied.

MOTS-CLÉS

Autorités hispaniques, corsaires, échange, commercial, négociations.

\section{SLEUTELWOORDEN}

Spaans gezag, piraten, handel, onderhandelingen. 


\section{Introducción}

El fenómeno de la piratería integró varios aspectos de la vida de la región Golfo-Caribe ${ }^{1}$ durante gran parte de la época colonial. A través de estos vínculos es factible caracterizar su participación en la historia del espacio de estudio. En términos generales y en la larga duración, el actuar de corsarios, bucaneros, filibusteros y piratas estuvo ligado, al menos, a las relaciones políticas y bélicas entre la Corona española y sus símiles francesa e inglesa, así como con los Países Bajos. Esto permite considerar al fenómeno un medio más a través del cual los poderes reales de Europa entraron en contacto (Bordejé Morencos, 1992, pp. 87, 175; Elliot, 2006, pp. 331-375; Kennedy, 2007, pp. 69, 90). En ese sentido, este fue punta de lanza para minar el poderío de la monarquía española en Europa, pero además fungió como mecanismo para abrir y ocupar espacios, por parte de otras coronas, en la América hispana.

En este entorno de confrontación entre los poderes reales, podemos señalar el empleo de estrategias defensivas españolas tanto

${ }^{1}$ El Golfo-Caribe es la expresión que sintetiza un dilatado y complejo espacio histórico, geográfico, económico y cultural. En otras palabras, constituye una región que abarca desde la península de La Florida, el Golfo de México y Yucatán, hasta la Guyana, pasando por la costa caribeña de Centroamérica, Panamá, Colombia, Venezuela, además de, por supuesto, las Antillas Mayores y Menores. Las características geográficas del Golfo-Caribe permiten mostrar pruebas suficientes para señalar que esta es una región conformada en la larga duración, en el marco del tiempo del medio físico y natural. El relieve, orografía, profundidades del mar, corrientes marítimas, régimen de vientos, clima y vegetación nos remiten a considerarla una unidad geográfica. Pero también la región fue tomando forma a partir de la expansión española en América, amén de que durante la época colonial fue campo de confrontación mundial entre diferentes Coronas, lo que la convierte en el antemural del Virreinato de la Nueva España. Otra observación sobre el Golfo-Caribe tiene que ver con la comunicación, a través del mar, tanto al interior como al exterior de la región. Cuando nos referimos a conexiones hacemos hincapié en el papel de las rutas navales como un medio que permitió todo en aquellos espacios. Así, los diversos puertos recibían y enviaban embarcaciones, hacia adentro y hacia fuera, cargadas con mercancías, papeles, ideas, animales, hombres, mujeres y un largo etcétera. Eran los nodos donde convergían las líneas que en conjunto tejieron una malla de vínculos marítimos que evidenció la unidad regional. Véase Von Grafenstein Gareis (1997, pp. 33-40; 2006, pp. 9-22); Von Grafenstein Gareis, Muñoz y Nelken (2006, pp. 101-103, 105); García Martínez (2009, pp. 20-21); De la O (2014, pp. xxvi-xxxvi). 
marítimas, a través de la organización de armadas (Pérez Turrado, 1992; Caballero Juárez, 1997; Andrade Muñoz, 2006), como terrestres, por medio de milicias españolas, así como de compañías de negros forzados a servir en la salvaguardia, agregando también, según el contexto, a indios (Serna, 2000; Quezada y Okoshi Harada, 2001, p. 93; De la O, 2013). A todo ello hay que sumar la construcción de trincheras, fortalezas, castillos, torres, murallas, entre otras edificaciones defensivas (Blanes, 2001; Victoria Ojeda, 2000; Casanova y Rocher, 1995; Muñoz, 2005). De tal manera se vislumbra que el fenómeno fue capaz de producir transformaciones en pueblos, villas y ciudades costeros, e incluso de tierra adentro, del Golfo-Caribe.

Pero esto no solo ocurrió gracias a la erección de ese repertorio de defensas pétreas, sino también por las alteraciones derivadas de los conflictos entre aquellos navegantes y la parte hispana. Ahora bien, en general, es posible apuntar que la defensa de los espacios costeros de la región involucró tanto a españoles como a sus descendientes y a grupos subalternos de la sociedad colonial.

El fenómeno implicó además la generación de corpus legales que regulaban el corso español y la vida tanto al interior de compañías milicianas como de quienes resguardaban y hacían funcionar las fortificaciones (Cruz Barney, 1997, 2009). Asimismo estuvo presente en el tráfico comercial entre metrópoli e Indias, en la distribución de mercancías americanas en Europa, y en el abastecimiento de productos y hombres a América provenientes del Viejo Continente y África (Solow, 1991, pp. 21-42; Lucena Salmoral, 1992, pp. 14-15; López Zea, 2003, p. 240; García de León, 2014, pp. 11, 41; Wolf, 2006, pp. 165-195; Delgado Ribas, 2007, pp. 45-71; Klein y Vinson III, 2013, pp. 38-39). Al respecto, García de León (2014, pp. 22-23) considera que el fenómeno de la piratería fue una de las piezas relevantes para armar el rompecabezas del capitalismo, debido a que impulsó la temprana globalización mercantil en los siglos XVI, XVII y XVIII. Este panorama deja en claro que tal fenómeno no estuvo reducido a robos, contrabando, amagos y agresiones en mar y 
tierra en la América colonial. El horizonte resulta amplio, complejo y multidimensional.

Si bien los aspectos anteriores representan puntos de partida para profundizar en la complejidad de la historia del fenómeno, lo cual conlleva sumergirnos también en el Golfo-Caribe, es importante señalar la pertinencia de adentrarnos más allá. En efecto, todo el conocimiento general sobre el fenómeno y la región ha soslayado inmersiones más detalladas en la esfera de las interacciones, generadas en el contexto de aquel, entre corsarios, bucaneros, filibusteros, piratas y la sociedad colonial de la región. Arrojar luz al respecto implica preguntarnos sobre las formas de interacción o convivencia entre unos y otros. Esto da pie a considerar la existencia de una multiplicidad de contactos entre aquellos navegantes y miembros de la sociedad colonial. Dentro del conjunto de vínculos nos enfocamos, en esta ocasión, en algunos ejemplos de negociaciones en entornos de intercambios comerciales con el fin de aproximarnos a historias "desde abajo", a nivel del mar. Esto tiene como finalidad reconstruir los procedimientos que hicieron posible la actividad comercial entre extranjeros y la sociedad colonial, es decir, los pasos que condujeron a los tratos y contratos. Con ello privilegiamos las relaciones cara a cara, establecidas, entre ingleses y franceses con españoles, en algunos espacios del Golfo-Caribe durante el siglo XVI. Salen a flote situaciones y hechos que apuntan a la conformación de una "economía práctica de cuanto es favorable al individuo y a su grupo" (Gonzalbo Aizpuru, 2009, p. 15). Con esto nos referimos a todas aquellas prácticas a través de las cuales se resolvieron tanto necesidades básicas como intereses comerciales, atendiendo al contexto específico en el cual se desarrolló el caso. Todo ello ayuda a comprender parte del proceso de inserción del fenómeno de la piratería en la vida del Golfo-Caribe. ${ }^{2}$

${ }^{2}$ Es relevante apuntar que uno de los ámbitos que derivaron de las negociaciones comerciales fue la creación de redes comerciales. Quienes dieron vida a esas redes solapaban la transgresión de las normativas coloniales en torno a las prácticas de los tratos y contratos. Su explicación es multidimensional. Tales asuntos están en espera de ser atendidos de forma detallada para al menos el siglo XVı y la centuria siguiente. Este 
Para llevar a cabo lo recién mencionado delimitamos nuestro trabajo dentro de los siguientes parámetros. En primera instancia dedicamos nuestra atención a los corsarios, por lo cual nos situamos en el siglo XVI, en la región ya indicada. Esto se debe a la documentación extraída del Archivo General de Indias, a partir del Portal de Archivos Españoles en red. Los datos obtenidos permiten reconstruir, con cierto lujo de detalle, la secuencia de las negociaciones de los casos que aquí presentamos. Así, nuestra metodología se concentra en el proceso completo de los acuerdos o desacuerdos mercantiles. Por lo tanto contempla señalar el arribo de las naves corsarias a algunos puertos del Golfo-Caribe, el desarrollo de los diálogos y la puesta en marcha de las compraventas. Exponemos tres casos. Uno sucedido en 1528 en el derrotero del capitán corsario Diego Yngenios, el cual se adentró a las Indias por mandado del rey francés Francisco I. Los dos restantes ocurrieron en 1563 y 1565. Ambos tuvieron como protagonista al inglés John Hawkins. Estos ejemplos están organizados atendiendo dos contextos de interacción. Proponemos agrupar, por un lado, los encuentros o comunicaciones en el contexto de intercambios comerciales directos pacíficos. Por otro lado, consideramos las interacciones en ámbitos relacionados con la violencia, en concreto, las exigencias de rescates emitidas por ingleses o franceses con el fin de evitar la puesta en marcha de agresiones sobre puertos, ciudades, embarcaciones y hombres. En ambos casos estamos hablando de intercambios entre cada una de las partes involucradas. De modo tal que los acuerdos y desacuerdos giraron en torno a la adquisición o no de mercancías -como pieles, azúcar-, alimentos -por ejemplo frutas, agua, carne, etc.-, esclavos, e incluso la toma o no de puertos y ciudades españoles por parte de ingleses y franceses.

artículo solo hará referencia a la distribución de las mercancías obtenidas en los intercambios, con el único fin de echar una mirada discreta a la reconstrucción de las redes de intercambio. Por lo tanto no representa un estudio sobre esto último, sino sobre los procesos de negociación; insistimos en ello. 


\section{Fenómeno de la piratería e intercambio comercial}

Ahora vamos a exponer brevemente las características fundamentales de cada uno de los aspectos que dan título a este apartado. Para iniciar conviene definir lo que aquí se entiende por fenómeno de la piratería. Podemos comenzar apuntando que esta frase refiere a un conjunto de procesos articulados en la larga duración, sobre todo en la época colonial y en aguas del Atlántico y el Pacífico americanos. Fue "una historia que poseyó dinámica propia que entre otras características logró irrumpir, trastocar y jugar un papel preponderante en la vida económica, política y cultural durante la época colonial" (De la O, 2014, p. iii). No obstante, es posible identificar, al menos en términos generales, procesos de mediana duración a partir de la entrada en escena y actuación de actores sociales.

En cuanto a las etapas del fenómeno, proponemos una primera que cubre de 1527 a 1620-1630, en la cual encontramos principalmente a los corsarios. ${ }^{3} \mathrm{O}$ sea, en una definición mínima, resultaban ser aquellos navegantes no hispanos que se adentraron a las aguas del Golfo-Caribe con la anuencia real de sus respectivos reyes (Azcárraga y de Bustamante, 1950, p. 28; Lucena Salmoral, 1992, pp. 35-37; López Zea, 2003, p. 12; García Venegas, 2003, p. 561; Moreau, 2012, pp. 31-32).

Una segunda etapa abarca de 1620-1630 a 1670, en cuyo lapso registramos la existencia patente de contrabandistas, así como el surgimiento de bucaneros y filibusteros. Estos últimos personajes representaron productos sociales americanos. De forma muy sucinta podemos apuntar las características primordiales de unos y otros. Los bucaneros eran una especie de cazadores de ganado cimarrón, del cual aprovechaban carne y pieles con el fin de aprovisionar barcos extranjeros. El epicentro de esta actividad fueron las bandas norte

${ }^{3}$ Cabe señalar que la definición aquí colocada solo hace referencia a una parte del cúmulo de aspectos que envolvió el término y la práctica del corso. Ahora se halla en dictamen un artículo, de quien estas líneas escribe, intitulado "Desde el poder y desde los hombres. Elementos para profundizar en las características de corso en el GolfoCaribe. Siglo XVI", para ser publicado en un dossier en la revista Caribbean Studies, de la Universidad de Puerto Rico. 
y occidental de la isla La Española. En cuanto a los filibusteros, este término derivó del empleo de un tipo de embarcación ligera para realizar actividades de saqueo en la mar. Filibusteros y bucaneros estuvieron presentes en los albores de la Cofradía de los Hermanos de la Costa (Lucena Salmoral, 1992, pp. 39, 150-156; García Venegas, 1997, pp. 101-105; Bernand y Gruzinski, 2005, pp. 536-538; García de León, 2004, p. 25; Franco, 2008, pp. 74-75; Gall y Gall, 2014, pp. 59-86, 92-141).

Por último, de 1670 a 1750 se desarrolló la época de la piratería. En esta fase hallamos como protagonistas a los piratas, los cuales básicamente eran navegantes dispuestos, en teoría, a llevar a cabo asaltos a cualquier barco o puerto sin importar la Corona a la que pertenecieran (López Zea, 2003, p. 12; De Jarmy Chapa, 1987, p. 129; Georget y Rivero, 1994, p. 19).

Lo anterior no implicó el monopolio absoluto del protagonismo de cada uno de los diferentes grupos de actores sociales en el marco del fenómeno de la piratería. Más bien resaltamos la mayor notoriedad de unos u otros a lo largo del tiempo. Aun así conviene subrayar la pertinencia de más estudios sobre la historia del fenómeno para afinar o modificar las temporalidades recién señaladas.

Ahora nos concentraremos en el asunto del comercio, específicamente, el comercio directo. La participación directa en la explotación de los recursos naturales y humanos de las Indias fue uno de los pilares principales que justificaron el arribo a América de naves de Coronas distintas a la española. En teoría, la monarquía hispana era la única que podía comerciar con el Nuevo Mundo, al menos de forma directa (De la O, 2014, pp. 8-22). En este contexto, el fenómeno de la piratería significó, en términos generales, un medio a través del cual era posible quebrantar la normatividad emitida por y mediante la Casa de la Contratación de Sevilla respecto a la presencia extranjera en Indias. Esto permite dar sentido y explicación a las diversas negociaciones comerciales, así como a algunas prácticas de violencia llevadas a cabo en el Golfo-Caribe. Adquirir algún tipo de botín fue uno de los objetivos centrales de corsarios, bucaneros, 
filibusteros y piratas. Así, tanto las negociaciones como la violencia, en el marco del fenómeno de la piratería, tuvieron como común denominador la obtención de recursos indianos.

Al emplear el término intercambio comprendemos "aqueIlas formas por las cuales los corsarios otorgaron o devolvieron productos y/o espacios urbanos a cambio de otra serie de enseres de diverso tipo" (De la O, 2014, p. 522). Un aspecto relevante a considerar es que los intercambios comerciales directos, contrabando y comercio directo son sinónimos para referir a un proceso histórico con su propia dinámica y desarrollo en América. Se trata del fenómeno del contrabando. En pocas palabras podemos definirlo como todo un conjunto de prácticas que propiciaron el contacto comercial directo entre extranjeros y súbditos de la Corona hispana, lo cual conllevó la violación de las normativas en tal materia. Cuando aludimos a esto último nos colocamos en el campo del Ilamado monopolio español sobre Indias. A modo de síntesis podemos decir que fue un proyecto de la monarquía española con el propósito de preservar para sí el espacio marítimo del Mar del Norte -océano Atlántico-y del Mar del Sur-océano Pacífico-, lo cual generó regulaciones para el control de actividades comerciales y el traslado de personas, entre otros aspectos. Nuestra perspectiva al respecto tiene como base la pretensión de un férreo control sobre el entorno marítimo que buscó la Corona española y no exclusivamente en el ámbito comercial. De hecho consideramos que este fue la parte más visible dentro de la historia de las regulaciones concernientes a las actividades llevadas a cabo en el mar (Haring, 1984, pp. 155-193; De la O, 2014, pp. 1-55).

Señalamos en líneas anteriores que el fenómeno coadyuvó a la expansión del capitalismo, pero esto solo fue el escenario general. García de León (2014) ofrece algunos aspectos relacionados estrechamente con el asunto comercial en el marco del fenómeno en cuestión. Además de propiciar encuentros violentos, el pillaje dio pie al funcionamiento del binomio piratería-comercio gracias a la generación de redes de intercambio que no estuvieron ubicadas 
únicamente en las costas sino también tierra adentro. En cercano vínculo con lo anterior, la actividad del contrabando ayudó asimismo a la creación de mercados internos. En ellos participaban, por lo menos, autoridades coloniales y vecinos. Esto condujo al establecimiento de pactos entre los hombres provenientes del mar y los ubicados en tierra. Al resquebrajarse estos acuerdos sucedieron enfrentamientos y agresiones entre unos y otros (García de León, 2014, pp. 22, 26-27).

Ahora bien, otra cuestión que estuvo involucrada en el marco de los intercambios fueron los rescates, vistos como una práctica que disimuló la actividad contrabandística en la región. Uno de los significados de la palabra rescate tuvo relación con "recobrar por precio lo que el enemigo ha robado". Esto último implicaba pactar con el "enemigo", ya fuera ante una amenaza o después de actos de violencia. Pero también encontramos otras definiciones en torno al término en cuestión. En la esfera comercial era entendido como "cambiar o trocar una cosa por otra". Además podía significar "redimir la vejación, libertar el trabajo u contratiempo" (Real Academia Española, 1737, p. 591, 1). ${ }^{4}$

Asimismo hallamos a las arribadas forzosas, la cuales fueron situaciones propicias para disimular, de otra forma, el contrabando; y a las arribadas maliciosas, que pueden catalogarse como una práctica sin maquillaje, o sea descarada, de comercio directo. Ambas se distinguieron por ocurrir cuando a las embarcaciones les era "forzoso" modificar el derrotero que oficialmente estaba señalado. Las situaciones comunes para justificar las arribadas eran las tormentas en la mar y la presencia de corsarios. Implicaban, por un lado, el desvío del derrotero establecido y, por el otro, daban pie a los rescates, es decir, realizar la venta de los productos que estaban en la nave que llevaba a cabo ambas prácticas. Pero era común que los fiscales de Su Majestad o de la Casa de la Contratación incluyesen en los cargos las arribadas maliciosas y descaminos (De la O, 2014, p. 525). Además de lo recién expuesto, el Ilamado comercio

\footnotetext{
${ }^{4} \mathrm{Al}$ respecto de los rescates véase De la O (2014: 523-524).
} 
de balandra entró en el escenario de las prácticas de comercio ilícito en costas, por ejemplo, de la Nueva España, según subraya García de León (2014). Esta actividad involucraba a embarcaciones de bajo calado que podían navegar sigilosamente las proximidades de las costas. Para romper la discreta navegación se hacía sonar un disparo de cañón con el cual se anunciaba la oportunidad para realizar tratos y contratos al amparo de la noche (García de León, 2014, p. 89). Este sintetizado esquema sobre el papel de la actividad comercial ilegal y su funcionamiento refiere al grado de penetración del fenómeno de la piratería en la vida económica del Golfo-Caribe. A pesar de que esto es conocido en la historiografía, aún quedan lugares grises o lagunas que evitan una mejor comprensión de estos procesos históricos.

Una vez expuesto lo anterior, conviene distinguir los espacios de interacción entre aquellos navegantes y la sociedad colonial. En términos generales, podemos identificar por lo menos tres espacios de interacción social en el contexto del corso, los cuales son también aplicables a las etapas posteriores del fenómeno de la piratería. El primero es el interior de las embarcaciones inglesas y francesas. En este ámbito encontramos a quienes fueron secuestrados o capturados por esos nautas, pero asimismo a aquellos que abordaron alguna nave como fiadores del cumplimiento de acuerdos de negociación entre corsarios y autoridades hispanas. El segundo es la costa. Aquí podemos distinguir por lo menos tres aspectos que motivaron contactos entre los navegantes extranjeros y la sociedad colonial del litoral: uno tuvo que ver con intercambios comerciales, otro con el abastecimiento de vituallas y agua, y uno más con ámbitos de violencia. El tercer espacio lo constituyen estancias, villas, ciudades y pueblos de indios ubicados tierra adentro. Con esto nos referimos a la incorporación de corsarios en alguna de las facetas de la vida lejos de las costas. En algunos casos estos personajes eran entregados a vecinos para integrarse a labores productivas en núcleos urbanos, talleres, estancias y minas. En este artículo nos situamos en espacios costeros. 


\section{Diego Yngenios y el cabildo de Nueva Cádiz de Cubagua}

Uno de los primeros registros de presencia corsaria en el Golfo-Caribe fue el derrotero del capitán, bajo lábaro francés, Diego Yngenios, en 1528. El contingente galo arribó a la ciudad de Nueva Cádiz, en la isla de Cubagua. Esta fue una de las incursiones iniciales a la región no solo por parte de la Corona francesa sino en la historia del fenómeno de la piratería. Esto sucedió en el contexto de confrontación entre Francia y España, el cual involucró al Caribe luego de que Francisco I, rey galo, "descubriese" las posibilidades que ofrecía América, recursos naturales que quedaban bajo extracción y explotación directa de la monarquía hispana.

El soberano francés empleó el corso como una estrategia para desgastar y, por supuesto, saquear en la mar a las embarcaciones españolas y portuguesas provenientes del Caribe. Con ello era posible participar de los beneficios de aquellas tierras allende el mar océano. En este sentido resulta plausible señalar que el caso de Yngenios marcó parte del comienzo de la historia de la actividad mercantil entre extranjeros y la sociedad colonial del Golfo-Caribe en el marco del fenómeno de la piratería durante la época colonial (Hoffman, 1980, pp. 24-27; De la O, 2014, pp. 62-75).

En este caso, el inicio de los acuerdos ocurrió luego de una batalla naval. En ella estuvieron involucrados algunos españoles e indios, los cuales se enfrentaron a los navegantes galos. A pesar de ello, la posibilidad de algún acuerdo comercial no fue eliminada. De hecho, fue el interés comercial el que dio pie a establecer el cese a las hostilidades y evitar la continuación de la batalla marítima en tierra. Los mercaderes que acompañaron al capitán Yngenios, a decir de este, indicaron que "pedían, los consejeros, no saltar en tierra y por tanto no pude hacer nada...". Pero también los españoles solicitaron detener las hostilidades e iniciar pláticas para realizar intercambio comercial: "acordé de hacer paces con los señores de la villa porque ellos me lo rogaron y que si traía alguna mercadería 
que las echase en tierra y que me harían buena compañía seguramente, sobre la corona real...". ${ }^{5}$

Se abrió, pues, el camino a la negociación entre las partes. ¿Quiénes participaron en ella? Los miembros del cabildo de la ciudad y el capitán Yngenios. Los integrantes del cabildo que encabezaron las negociaciones eran Pedro de Herrera, alcalde mayor de Cubagua y de la costa de Tierra Firme, así como Alonso de Rojas y Andrés Fernández, regidores y vecinos de la villa. Pero además encontramos a otros personajes que no formaban parte del cuerpo del cabildo. Juan Roseo, maestre de una nao Ilamada Santa Ana, y un religioso de la Orden del Carmen, nombrado fray Simón. A ellos se sumaron otros dos hombres, Juan de Ynar y Sión Aseo. ${ }^{6}$ Estos últimos fungieron como testigos de las negociaciones.

Al acuerdo de no hostilidades procedió la autorización del cabildo para el desembarco de las mercancías extranjeras junto con los mercaderes y demás hombres franceses. Una vez permitido, prosiguió generar un marco de seguridad para ambas partes. Las autoridades garantizaron un seguro para que los galos anclasen frente a la ciudad y descargasen los productos que deseaban comercializar. Así fue redactado,

por la presente aseguramos debajo de nuestra fe y palabra y haciendas a vos el capitán Diego Yngenios y a Jacques Fen, mercader [...] para que podáis venir a tierra a esta isla con toda la hacienda y mercaderías que quisieredes y por bien tuvieredes para las vender pagando los derechos debidos a Su Majestad de las cosas que así se vendieren [y] de lo que así guardes en tierra y lo que no se vendiere a vuestro contento lo podáis volver a la dicha nao y a donde quisieredes...7

${ }^{5}$ Archivo General de Indias (en adelante AGI), Santo Domingo 9, n. 28. Carta de Diego Yngenios. La Mona a 22 de agosto de 1528, f. 70r.

${ }^{6}$ bíd., f. $71 \mathrm{v}$.

${ }^{7}$ Ibíd., f. 71 v.-72r. 
Por supuesto, toda esta actividad comercial se llevaría a cabo en el acuerdo de no agresión, lo cual implicaba una serie de beneficios que otorgaban los españoles a los franceses. El cabildo afirmó que los galos no serían violentados en sus personas ni en las mercaderías que sacasen a tierra. Asimismo estaba incluida la seguridad para las embarcaciones no hispanas, además de que los franceses podían transitar libremente de la tierra al mar. El documento lo indicó del siguiente modo:

y vos aseguramos que vosotros ni ninguno de vos no seréis enojados ni maltratados en vuestras personas ni en las dichas mercaderías ni haciendas que así trajeredes ni menos los bateles y gente que en ellos vinieren antes podrán ir y venir y estar en esta isla el tiempo que quisieres en paz y en salvo sin que persona ninguna de esta isla los enoje...8

Inclusive, para mayor seguridad en los intercambios comerciales, los cabildantes entregaron en custodia de los galos a dos personas, las cuales eran la fianza que daba más certeza a las promesas hispanas para con aquellos navegantes extranjeros,

para que más seguro seáis decimos que daremos dos personas de bien que estén en la dicha vuestra nao en tanto que el dicho mercader y las otras personas aquí nombradas estuvieren en tierra beneficiando las dichas mercaderías todo a vuestro sabor y contento... ${ }^{9}$

Ahora bien, el seguro emitido por el cabildo de Nueva Cádiz también incluyó las obligaciones que adquirían los corsarios franceses. En esencia, los extranjeros no podían emprender ningún acto bélico en contra de la ciudad, de sus habitantes ni de embarcación alguna que surcase las aguas cercanas a Cubagua durante el tiempo que durase la venta y cobranza de las mercaderías. Así estaba estipulado en el texto,

${ }^{8}$ Ibíd., f. 72r.

${ }_{9}^{9}$ lbíd. 
entiéndase esta con tanto que nos deis otra tal fe y seguridad que en tanto que dura la venta y cobranza de las dichas mercaderías que no nos enojareis con la nao ni carabela ni bateles ni artillería ni rastros de pesquería a nosotros ni a ningún navío ni barco que estén ni a los que vinieren a esta isla de España y de otras partes... ${ }^{10}$

Hasta aquí podemos señalar que el acuerdo para realizar la descarga de las mercancías en Nueva Cádiz aparentaba ser claro. La negociación estuvo sostenida en el visto bueno de las autoridades del cabildo y en la recíproca fe de no agresión. Sin embargo, tal parece que al capitán Yngenios no tenía aún suficiente confianza; necesitó de una reafirmación de la fe de salvaguardia que los españoles le ofrecieron. El alcalde mayor, Pedro de Herrera, optó por hacer hincapié al respecto, no sin antes solicitar mayor claridad en las peticiones hechas por el mencionado capitán, "os debéis señor aclarar que es lo qué queréis y pedís porque hasta aquí no habéis señalado ni dicho a qué sois venido ni lo que queréis de estos señores y para esto es menester que señor os aclaréis...". ${ }^{11}$ La misiva no se encuentra dentro del expediente que guarda esta parte de la historia que nos ocupa. El cabildo volvió a escribir al capitán Yngenios declarando mayor especificidad en cuanto a los términos del acuerdo de no hostilidades:

podréis saltar en tierra, vuestra persona y diez o doce gentiles hombres y más que los mandares, sobre mi fe y palabra y sobre seguro de la corona real de nuestro excelente y grande emperador. Por la cual os prometo que no seáis enojado de persona de esta isla vos ni otro de los vuestros, antes se os hará toda cortesía y buen tratamiento como se tiene de costumbre de hacer a todos los caballeros y otras personas forasteras que a ella vienen como podéis saber de esos hombres que allá tenéis... ${ }^{12}$

${ }^{10}$ Ibíd., f. 72 r.-v.

${ }^{11} \mathrm{AGl}$, Santo Domingo 9, n. 28. Carta del alcalde mayor de Cubagua, Pedro de Herrera. Nueva Cádiz a 26 de julio de 1528, f. 72 v.

${ }^{12}$ Ibíd., f. 72v.-73r. 
Así pues, el capitán Yngenios ordenó el desembarco de las mercancías,

y con esta confianza eché la mercadería en tierra y al maestre y a tres hombres con él para vender la mercadería, la cual mercadería se vendió y que [por] ella habían de pagar al cabo de tres días con perlas... ${ }^{13}$

Con el traslado a tierra y exposición de las mercancías iniciaban otras negociaciones entre quienes ofertaban y aquellos interesados en adquirir cada uno de los bienes europeos que en aquella ocasión entraban a Nueva Cádiz. En efecto, los productos traídos por los galos fueron descargados y vendidos a los vecinos. Desafortunadamente, la documentación no brinda más datos respecto a cómo se llevó el proceso de compraventa y la distribución de las mercancías entre aquellos que las adquirieron.

Hasta aquí, aparentemente, el intercambio comercial se desarrolló sin inconveniente alguno. Empero, el cierre de las negociaciones mercantiles no se llevó a cabo. En pocas palabras podemos decir que una de las partes incumplió sus compromisos emanados del acuerdo. Pedro de Vilches, vecino de Nueva Cádiz, indicó que los franceses fueron traicionados por los españoles. Este personaje apuntó que en efecto hubo un acuerdo, al cual se refirió de la siguiente forma: "fue el concierto que en tanto que la mercadería y ellos [los franceses] estuviesen en tierra que diesen los dichos señores [del cabildo] dos hombres de bien para más seguridad y en rehenes...". ${ }^{14}$ De Vilches describió así la captura de los franceses y la confiscación de las mercaderías,

y estando los franceses en tierra vendiendo sus mercaderías, el lunes tres de agosto, fue el batel de los dichos franceses en tierra y como lo tomaron allá, con veinte hombres y los mercaderes los detuvieron

${ }^{13}$ AGI, Santo Domingo 9, n. 28. Carta de Diego Yngenios. La Mona a 22 de agosto de 1528, f. 70r.

${ }^{14} \mathrm{AGl}$, Santo Domingo 9, n. 28. Carta de Pedro de Vilches. Nueva Cádiz, agosto de 1528, f. 73 r. 
estando yo y otro hombre en rehenes, y los dichos franceses cuando vieron la traición que les habían hecho hiciéronse a la vela con nosotros... ${ }^{15}$

Básicamente, los galos cayeron en una emboscada hispana. Los españoles Ilevaron por el camino de la negociación su estrategia para capturarlos. Al respecto, Diego Yngenios dijo que "un día antes de la paga tomaron la mercadería y la gente que estaba con el dicho maestre y echaronlos en la cárcel y la mercadería repartierónla entre ellos mismos...". Esta situación colocó en letra muerta el acuerdo al que supuestamente habían Ilegado ambas partes. Inclusive, el capitán de la nao gala afirmó que en dos ocasiones le fue ofrecido que saltase a tierra con el fin de aprehenderlo, según comprendió más tarde al ver cómo tomaban a parte de sus hombres. En efecto, desde la perspectiva del corsario, los españoles le ofrecieron beneficios para que desendiose y así lograr su captura. El primer intento lo realizaron tres hombres: uno Ilamado Barrio Nuevo, otro Villa Corta y uno más Antón de Jaén. Todos ellos, en palabras de Yngenios, "se me encomendaron mucho de hacer muchos bienes pensando que iría con ellos en tierra para hacerme la traición que habían pensando, y como no la hicieron contra mí acordaron de hacerla a los mercaderes...". ${ }^{16}$ La segunda intentona la llevó a cabo de nueva cuenta Antón de Jaén el mismo día que se efectuó la emboscada. De esta forma lo narró Yngenios,

comiendo y bebiendo conmigo en mi nao y se me ofreció de me hacer muchas mercedes y todo con traición pensando que yo fuera con él a tierra. Y después como no pudo llevarme prometió de me dar una pipa de agua fresca, porque la mía no era buena, y entonces mandé el batel por ella con doce hombres y la pipa de agua que me enviaron fue tomarme la gente y el batel... ${ }^{17}$

${ }^{15}$ Ibíd., f. 73r.-v.

${ }^{16} \mathrm{AGl}$, Santo Domingo 9, n. 28. Carta de Diego Yngenios. La Mona a 22 de agosto de 1528 , f. 70 r.-v.

${ }^{17}$ Ibíd., f. $70 \mathrm{v}$. 
Luego de todo ello el capitán galo manifestó su visión sobre los españoles y sus actitudes. Su malestar quedó expresado en una misiva a la Real Audiencia de Santo Domingo. Al respecto subrayó la deshonra que los súbditos del rey hispano hicieron a su Corona, al no respetar un acuerdo amparado a la sombra de esta,

y pensando que guardaran la corona de su rey, como los franceses guardan la corona del suyo cuando prometen y dan seguro sobre la corona real o morirán o lo han de cumplir lo que prometen sobre la corona real. Y esto me ha hecho fiarme de ellos y me ha hecho echar la mercadería en tierra... ${ }^{18}$

Toda esta situación, según Yngenios, traería consigo desconfianza en los acuerdos tomados con los españoles, "y esto será castigo para mí y para otros franceses que no traerán más ningún seguro de los españoles pues que no lo mantienen y no tienen su fe como hidalgos...". ${ }^{19}$

Pero esta probable simulación de toma de acuerdos ¿fue acaso un modo de estar a favor del rey español?, ¿solo fue una estrategia para acceder a las mercancías francesas y, por lo tanto, responder a las necesidades inmediatas de abastecimiento de la población en Nueva Cádiz? Además, cabe preguntarse si esta reacción hispana estuvo relacionada con la ausencia de alguna estrategia de defensa marítima enfocada a responder incursiones de naves extranjeras, teniendo en cuenta que el arribo del capitán Yngenios y su gente fue el segundo registro de presencia corsaria en el Caribe (De la O, 2014, pp. 115-118). En el marco de esta novedad, en cuanto a la llegada de la nave gala, es propicio interrogarse respecto a si la estratagema española fue una medida ejecutada ex profeso por el cabildo ante la falta de disposiciones del poder real en torno a la entrada de extranjeros a las Indias sin licencia real. A pesar de no poseer más información para dar respuesta puntual a estos cuestionamientos, es factible señalar que desde los comienzos del fenómeno de la

\footnotetext{
${ }^{18}$ Ibíd., f. 70r.

${ }^{19}$ Ibíd.
} 
piratería existió interacción de corsarios con por lo menos una parte de la sociedad colonial del Golfo-Caribe. De hecho observamos dos momentos de negociación, uno llevado a cabo entre el capitán Yngenios y las autoridades y otro entre los mercaderes franceses y la población en general, lo cual se traduce en la obtención del visto bueno oficial, por un lado, y en la venta de las mercancías a vecinos y demás gente en el lugar, por el otro.

\section{Negociaciones y alianzas comerciales de John Hawkins en la costa norte de La Española (1563)}

Durante los años sesenta del siglo XVı los ingleses comenzaron a ingresar al espacio Golfo-Caribe. Uno de los que abrió camino fue John Hawkins. Las entradas de este navegante a las Indias occidentales tuvieron como principal interés el comercio. De hecho, sus expediciones a la región dieron inicio al paulatino incremento de la presencia inglesa, la cual fue patente hacia 1572; asimismo representó la apertura del comercio inglés en América (De la O, 2014, pp. 217-261; De Ita Rubio, 2001, pp. 101-105). El funcionamiento de la actividad mercantil anglosajona fue en esencia el siguiente: primero se intercambiaban manufacturas inglesas por esclavos en África, aunque también había entradas furtivas para capturar a los aborígenes sin mediar trato ni contrato alguno; luego los esclavos era cambiados por productos coloniales en el Golfo-Caribe, como plata, perlas, azúcares, cueros, etc.; por último, todo ello era trasladado hasta Inglaterra, donde eran procesadas las materias primas. A esto podemos Ilamarlo comercio triangular (García de León, 2014, pp. 102-103). Lo anterior resulta relevante porque John Hawkins impulsó este tipo de comercio a través de sus viajes al Nuevo Mundo. Eran las piezas de esclavos la base de todo ello. En pocas palabras, Hawkins puede ser catalogado como un actor fundamental para la consolidación del contrabando o comercio directo en cuanto actividad pilar de la economía americana. De ahí que las negociaciones entabladas por él sean de particular interés para 
comprender tal fenómeno. En este apartado y en el siguiente contamos con mayor información para reconstruir una parte de las negociaciones establecidas en los viajes del capitán.

El derrotero del primer viaje realizado por John Hawkins lo Ilevó a La Española, específicamente a la banda norte de esa isla en 1563. Ahí logró efectuar intercambios directos con los vecinos de Puerto de Plata, La Isabela y Monte Cristi. La armada de Hawkins estaba compuesta por tres embarcaciones,

navíos gruesos de porte cada uno de 200 toneladas y una carabela de porte de 100 toneladas y un patax los cuales navíos traían ingleses luteranos y más de 300 negros con muchas mercaderías de lencerías y sedas y otros rescates lo cual habían robado en la costa de Guinea y trían gente de guerra con muchas armas y artillería... ${ }^{20}$

En primera instancia cabe destacar cuáles fueron las explicaciones en torno al arribo de las naves inglesas. Como ya dijimos, la razón cardinal de los viajes de Hawkins fue el interés comercial. No obstante, Pedro de Santisteban, uno de los que comerció con el inglés, indicó que la llegada de aquel capitán anglosajón a costas del norte de La Española fue una arribada forzosa, expresándolo así: "aportó al dicho Puerto de Plata con tormenta grande...". ${ }^{21}$ Tomás Antonio, el almirante de la flota de Hawkins, afirmó que "procede de unos negros que llevó de Guinea a Santo Domingo los cuales le dijo que los llevaba a Tenerife y con tiempo forzoso arribó a Santo Domingo...". ${ }^{22}$ Sin embargo, en un registro documental sobre el viaje de Hawkins no aparece nada al respecto (Hakluyt, 1904 [1586], vol. X, p. 8).

El primer puerto al que arribó la armada de Hawkins fue Puerto de Plata. Ahí, de acuerdo con el testimonio de Guillermo

${ }^{20}$ AGl, Justicia 999, n. 2, r. 2, pieza 2. Cabeza de información. Madrid a 12 de diciembre de 1565, f. $114 \mathrm{v}$.

${ }^{21}$ AGl, Justicia 999, n. 2, r. 2, pieza 2. Probanza de Cristóbal de Santisteban. Santo Domingo a 29 de agosto de 1566, f. 4v.

${ }^{22}$ AGl, Justicia 870, n. 7. Declaración de Utitón. Sevilla a 13 de septiembre de 1563, f. 31 v. 
de Borrero, las naves inglesas no lograron soltar anclas ni abrir las negociaciones para realizar algún intercambio comercial. Según la versión de Cristóbal de Santisteban, Hawkins, al llegar a ese puerto, envió en un batel a ciertos hombres para hacer saber al capitán Francisco de Ceballos y al cabildo de aquella villa que:

no recibiesen alteración de que él hubiese llegado con su armada al dicho puerto por que lo había causado una gran tormenta que había tenido y que él venía para darles todo gusto y contentamiento y que él era servidor de Su Majestad y que él quería entrar en el dicho puerto como amigo si le daba para ello licencia... ${ }^{23}$

De hecho, el capitán inglés expuso a "los dichos esclavos y mostró carta de pago de ellos y de los derechos que por la compra y saca de los dichos esclavos se debían al serenísimo rey de Portugal y a sus oficiales...". ${ }^{24}$ Explicar las supuestas razones por las cuales las naves inglesas habían arribado a Puerto de Plata podemos considerarlo el primer paso para entablar negociaciones comerciales entre aquellos navegantes y los habitantes del lugar.

No obstante, la Audiencia de Santo Domingo, al Ilegarle la notificación de la presencia anglosajona, estipuló, por un lado, que "ninguna personas no [sic] tratase con los dichos ingleses...". Por otro lado, ordenó que el licenciado Bernáldez fuese como capitán a hacer frente a los extranjeros. Este personaje se unió al tesorero Francisco de Ceballos en Puerto de Plata. Según Guillermo de Borrero, los españoles "fueron a aprender a los dichos ingleses y no pudieron prenderlos por estar en la mar en sus naos a punto de guerra...". ${ }^{25}$ Diferente la versión del cabildo de Puerto de Plata, pues los cabildantes, "temiéndose del dicho John Hawkins y de la armada que traían, le enviaron a decir que 10 leguas de ahí estaba un puerto que se Ilamaba La Isabela que ahí podría estar con su

${ }^{23}$ AGI, Justicia 999, n. 2, r. 2, pieza 2. Probanza de Cristóbal de Santisteban. Santo Domingo a 29 de agosto de 1566, f. $4 \mathrm{v}$.

${ }^{24} \mathrm{lbíd}$.

${ }^{25}$ AGI, Justicia 870, n. 7. Testimonio de Guillermo de Borrero. Sevilla a 21 de agosto de 1563 , f. 5 r. 
armada..."; inclusive un piloto hispano fue el encargado de conducir las naves hasta La Isabela. ${ }^{26} \mathrm{Si}$ bien con estas citas es factible destacar que los españoles no confiaron en las intenciones de Hawkins, no implicó, probablemente, un enfrentamiento armado entre ambas partes. Ahora bien, el testimonio de De Borrero señaló algo distinto al afirmar que "vio cómo llegaron al dicho Puerto de Plata tres navíos ingleses y llegados, la gente del pueblo no les consintió tomar puerto defendiéndole con tiros de artillería la entrada...". ${ }^{27}$ Aunque los restantes documentos utilizados para reconstruir esta historia no indican algo al respecto, no podemos negar o afirmar el empleo de los cañones españoles; en cambio, sugerimos que la desconfianza de los españoles salió a flote.

Entonces, los ingleses pasaron a La Isabela. Según De Borrero, la gente de Hawkins logró tomar puerto "por no haber gente y ser inhabitable...". ${ }^{28}$ De hecho, el capitán inglés, al parecer, dejó La Isabela porque era un puerto "desierto...". Antes de ello, envío una carta a la Real Audiencia de Santo Domingo exponiendo las mismas razones por las cuales arribó de forma forzosa a La Española:

dándoles aviso de cómo en la costa de Guinea le había sucedido una gran tormenta de que venía maltratado y que aportó en la dicha tormenta al dicho puerto y que les pedía y suplicaba le diesen licencia para que vendiese y contratase en la dicha isla los negros que traía y que él quería pagar a Su Majestad sus derechos y todo lo que era obligado... ${ }^{29}$

Sin embargo, el registro inglés de este primer viaje de Hawkins refiere a que este capitán sí contrajo relaciones comerciales en aquel puerto, "comerció [en La Isabela] con sus productos ingleses y con parte de los negros..." (Hakluyt, 1904 [1586], vol. X, p. 8). Pero no tenemos más detalles al respecto.

\footnotetext{
${ }^{26}$ Ibíd., f. 4v.-5r.

${ }^{27}$ lbíd., f. 4v.

${ }^{28}$ Ibíd., f. 5 r.

${ }^{29}$ Ibíd.
} 
Por su parte, los españoles no dejaron de buscar la captura del capitán inglés y su gente. Según la probanza de Cristóbal de Santisteban, la Real Audiencia de Santo Domingo pretendió tomar presos a los ingleses,

secretamente proveyeron un capitán y gente que fuese al dicho puerto de la Isabela [...] y que por estar como estaba poderoso el dicho Juan Aquines con su armada en el dicho puerto no pudo el dicho capitán ni gente poner en efecto lo que mandaron y el dicho presidente y oidores y así se volvieron sin hacer nada... ${ }^{30}$

Este intento no fructificó. John Hawkins ordenó dirigir velas de sus naves a Monte Cristi. ${ }^{31}$ La intención de los hispanos por tomar a los nautas extranjeros quizá fue solo eso.

Pero este propósito de poner fin a la navegación de los anglosajones en la costa norte de La Española no fue compartida por todos los españoles. Teniendo como base la declaración de De Borrero, es posible señalar que De Ceballos y Bernáldez lograron hacer contacto pacífico con el capitán Hawkins y entablar negociaciones para que le fuese otorgada licencia de comercio, al capitán inglés, por parte de aquel licenciado y tesorero. En efecto, Hawkins buscó aparentemente sin éxito en Puerto de Plata y La Isabela una licencia de las autoridades hispanas para justificar el intercambio comercial. Tal era un paso importante para llegar a su objetivo. El precio que alcanzó la autorización fue alto, "le sacaron al dicho capitán inglés cien negros para Su Majestad diciendo que harían darle licencia [...] y que dando los dichos negros nunca le dieron la dicha licencia...". ${ }^{32}$ Sobre esto, Fernando de Herrera aseguró que los ingleses propusieron que "les daban los dichos esclavos con cargo que les dejasen vender los demás que les quedasen y habían en sus navíos y cargarlos de cueros y azúcares...". Tanto De Ceballos como

${ }^{30}$ Ibíd., f. 5v.

${ }^{31}$ AGI, Justicia 999, n. 2, r. 2, pieza 2. Probanza de Cristóbal de Santisteban. Santo Domingo a 29 de agosto de 1566, f. $5 \mathrm{v}$.

${ }^{32}$ AGI, Justicia 870, n. 7. Testimonio de Guillermo de Borrero. Sevilla a 21 de agosto de 1563 , f. 5 r.-v. 
Bernáldez estuvieron de acuerdo en ello, garantizándole al capitán inglés que "si dentro de cierto tiempo Ilevasen cédula de Su Majestad para que se volviesen se los volverían...", pero finalmente aquel par de españoles "no les quisieron dar licencia para vender libremente los más esclavos...". ${ }^{33}$ De hecho, Hawkins comerciaba "sin confiar en los españoles más allá de lo que sus propias fuerzas le permitían..." (Hakluyt, 1904 [1586], vol. X, p. 8).

Empero, cabe la posibilidad de que De Ceballos y Bernáldez en realidad concretaron el acuerdo comercial, aunque, para no ser inculpados por ello, afirmaron lo que ya apuntó De Borrero. En pocas palabras, se trataría de un soborno. Es decir, que la entrega de ese centenar de negros implicó el otorgamiento de la licencia que daba visto bueno a la próxima actividad mercantil. Lo anterior viene a indicar el manejo de instrumentos jurídicos, por parte de los españoles, para colocar en el campo de lo legal lo que estaba fuera de las disposiciones. Un testimonio al respecto puede sustentar esta última posibilidad. Gabriel Fernández, un vecino de la isla de Tenerife, señaló que Hawkins envió

a un inglés, que no sabe su nombre, a Santo Domingo a pedir licencia al Presidente y Oidores para poder vender los dichos esclavos y lo que más llevaban, y este testigo entendió que se la dieron porque les dieron, para Su Majestad de los derechos, ciento y tantos negros... ${ }^{34}$

Asimismo, podemos hablar aquí de un marco de desconfianza mutua entre ingleses y españoles. Por un lado, la orden de captura emitida por la Real Audiencia, así como el probable engaño sufrido por el capitán anglosajón, y por otro, la cautela y medidas de seguridad puestas en marcha por este. Tal situación permeó la búsqueda y negociaciones emprendidas por Hawkins para dar salida a los negros y recibir productos indianos. En el puerto y villa de

${ }^{33}$ AGI, Justicia 870, n. 7. Testimonio de Fernando de Herrera. Sevilla a 21 de agosto de 1563 , f. 8 r.

${ }^{34} \mathrm{AGl}$, Justicia 870, n. 7. Testimonio de Gabriel Fernández. Sevilla a 12 de septiembre de 1563, f. $17 \mathrm{v}$. 
Monte Cristi, los ingleses "vendían escondidamente los dichos esclavos a trueco de cueros y dinero...", pero además de no haber estado pública y abiertamente realizando la compraventa, los ingleses cuidaban la integridad del capitán, "y que el dicho capitán inglés no saltaba en tierra y si alguna vez saltaba era muy apercibido...". ${ }^{35}$ Sin embargo, esto no fue todo. Muy probablemente estas circunstancias obligaron al capitán anglosajón a llevar a cabo una estrategia que le permitió intercambiar a los negros que capturó en Guinea por productos de La Española. Nos referimos al empleo de un intermediario entre los extranjeros y los españoles, papel que fue desempeñado por Cristóbal de Santisteban.

En primer lugar hay que decir que Cristóbal de Santisteban fue un hombre vinculado a las empresas comerciales. Su padre, Baltasar de Santisteban, ocupó el cargo de Contador Mayor de Cuentas de Canarias cuando Cristóbal dejó tal oficio. Su hermano, Pedro de Santisteban, era comerciante y vecino de la ciudad de Santo Domingo. Ambos trabajaron en el comercio al interior del Caribe. Así, Cristóbal "ha ido donde las islas Canarias a Santo Domingo y de Santo Domingo a las demás partes de las Indias que tiene declaradas con naos cargadas de mercaderías del dicho su hermano...". Pero también estuvo viviendo en Indias; en 1565 llevaba poco más de diez años residiendo en Santo Domingo, y de ahí navegó a San Juan Bautista de Puerto Rico, Cabo de Vela y Cartagena de Indias. Incluso fue el depositario de

...toda la grana y de los cueros y azúcares y otras cosas que llevaban que dieron a él al través de la flota que llevaba Pedro Menéndez en que sirvió a S.M. en embarcarlo y registrarlo y aviarlo para estos reinos a la ciudad de Cádiz... ${ }^{36}$

Cristóbal de Santisteban ingresó al escenario de la historia del corso en el Golfo-Caribe cuando entabló interacción con John

${ }^{35}$ AGI, Justicia 870, n. 7. Testimonio de Guillermo de Borrero. Sevilla a 21 de agosto de 1563 , f. 5 v.

${ }^{36}$ AGI, Justicia 999, n. 2, r. 2. Confesión de Cristóbal de Santisteban. Madrid a 3 de diciembre de 1565, f. 1 r.-v. 
Hawkins. Participó en la compra de algunos de los negros transportados por aquel inglés, y formó parte de los hombres que fueron entregados para dar constatación de los acuerdos comerciales, entre anglosajones e hispanos, y así generar un marco de seguridad mutua. El cabildo de Monte Cristi, así como vecinos, maestres y marineros, desconfiaban de Hawkins y tenían temor de que "les había de hacer mucho daño así en la tierra como en las mercaderías que estaban en los dichos tres navíos y temerosos de esto y que no echase gente en tierra para les hacer daño...". Aquellos tres navíos eran naves españolas que estaban surtas en aquel puerto cargando productos cuando arribó la flota de Hawkins. Este, por su parte, "había dicho y publicado que quería tratar como amigo...". El acuerdo entre las partes fue intercambiar rehenes con el fin de concertar un marco de seguridad mutuo, "para que tuviesen de esto cierto diese en rehenes algunas personas principales de las que traía en su armada y que ellos darían una persona principal que tuviese en su compañía en sus navíos...". ${ }^{37}$ Según De Santisteban, fue don Diego de Ribera quien facilitó que John Hawkins y Tomás Antonio entrasen a la vida del hombre en cuestión; De Ribera "puso a este declarante en rehenes en ciertos navíos de los dichos ingleses..." ${ }^{38}$ En una carta escrita por De Santisteban a Utitón, un comerciante inglés avecindado en Sevilla, aquel señalaba la servidumbre a un caballero como lo era el capitán anglosajón, "el valor de tan buen caballero como es el señor John Hawkins me ha obligado muy y mucho a servirle todos los días de mi vida...". ${ }^{39}$

Cristóbal de Santisteban fue una pieza importante para la actividad comercial de los anglosajones, "en todos aquellos pueblos de Puerto de Plata y Monte Cristi que se había aliado y confederado con los dichos ingleses y tomado mucha amistad con ellos...". Uno de los

${ }^{37}$ AGl, Justicia 999, n. 2, r. 2, pieza 2. Probanza de Cristóbal de Santisteban. Santo Domingo a 29 de agosto de 1566, f. $6 r$.

${ }^{38}$ AGl, Justicia 999, n. 2, r. 2. Confesión de Cristóbal de Santisteban. Madrid a 3 de diciembre de 1565, f. $1 \mathrm{v}$.

${ }^{39}$ AGl, Justicia 870, n. 7. Carta de Cristóbal de Santisteban. Monte Cristi a 10 de junio de 1563, f. 32r. 
aspectos relevantes que dieron sustento a esta alianza fue el poder que Hawkins otorgó a De Santisteban para que este, en nombre de aquel, realizase la compra y venta de los negros esclavos en aqueIlos puertos: "por cuya causa le dieron poder para que hiciese sus negocios...". Esto definió el papel que jugó De Santisteban en los intercambios comerciales y envío de mercancías a Sevilla, todo ello mientras aquel español estaba como rehén. Su papel incluyó, precisamente, figurar como responsable e intermediario en la compra y venta de las mercancías inglesas, "hacía las contrataciones de la venta de los dichos esclavos...". Esto mismo afirmó Fernando de Herrera: "concertaban a los dichos ingleses con los vecinos de la isla en la venta de algunos esclavos...". Ahora bien, gracias al testimonio de Gabriel Fernández podemos aproximarnos al costo que alcanzaron los esclavos ofertados por Hawkins: "así los dichos ingleses vendieron los dichos negros cada uno de ellos a cien cueros vacunos y otros a cien ducados y otros a más precio como podían...". Lograron obtener alrededor de 2500 cueros y 500 ducados. De Santisteban recibía una remuneración por las ventas efectuadas, "que el cobraba el premio que por ello le daban...". Así, era el receptor de las mercancías españolas para enviarlas a las naves de Hawkins, "según se concertaban y les enviaba las mercaderías de cueros, azúcares, dineros que por ellos les daban a los navíos ingleses asimismo y por esta orden se vendieron todos los demás negros que iban en los dichos navíos...". ${ }^{40}$

Pero la participación de Cristóbal de Santisteban no se redujo a lo anterior; además se encargó de fletar una urca, maestre Alonso de Campos, y un navío, dueños Francisco de Ceballos y Francisco Núñez. Ambas embarcaciones estaban cargadas de cueros y mercaderías con destino final España. Esta también fue una tarea que estuvo plasmada en el poder que el capitán inglés dio a De Santisteban.

${ }^{40} \mathrm{AGI}$, Justicia 870, n. 7. Testimonio de Guillermo de Borrero. Sevilla a 21 de agosto de 1563, f. 5v.-6r.; AGl, Justicia 870, n. 7. Testimonio de Fernando de Herrera. Sevilla a 21 de agosto de 1563, f. 8r.; AGl, Justicia 870, n. 7. Testimonio de Gabriel Fernández. Sevilla a 12 de septiembre de 1563, f. 17v.; AGI, Justicia 870, n. 7. Testimonio de Herirán Castellón. Sevilla a 12 de septiembre de 1563, f. 21v. 
Así lo indicó el propio Hawkins,

y para que por mi y en mi nombre podáis registrar y registréis todo el cualesquier cueros y azúcares y otras mercaderías en el registro de Su Majestad que van y que yo tengo cargadas en la urca de que es maestre Alonso de Campos y carabela maestre Pedro de Estrada, y los podáis consignar a los reinos de España a Utitón inglés y a Richarte Elasso, vecino de Sevilla y Cádiz, al precio y precios que por ellas quisieres dar de fletes de las dichas mercaderías y para hacer y hagáis todos los demás autos y diligencias... ${ }^{41}$

En síntesis, De Santisteban no solo fue un intermediario para la venta de los productos ingleses, sino que asimismo fungió como una especie de prestanombres del capitán Hawkins. A través de aquel español, las mercancías obtenidas podían ingresar al mercado sevillano de forma legal.

Todo ese cargamento le pertenecía a John Hawkins. De hecho, el propio capitán mencionó que la urca y el navío español tuvieron que emplearse por la cantidad de mercancías que lograron obtener, "y por vía de trueque, recibió tal cantidad de mercancías que no sólo Ilenó los tres barcos con pieles, azúcares, jengibre y perlas, sino que tuvo que fletar otros dos con cueros y otros productos..." (Hakluyt, 1904 [1586], vol. X, p. 8). Cristóbal de Santisteban señaló que él fue quien propuso a Hawkins el envío de las mercancías obtenidas a España,

aconsejó que los enviase a la dicha Casa de la Contratación de Sevilla registrado y juntamente con ello enviase a su almirante, y que fue público y notorio que no embargante que venía registrado en cabeza de este declarante eran bienes del dicho inglés... ${ }^{42}$

En efecto, De Santisteban resaltó el papel que desempeñó en el registro de las mercancías enviadas a Sevilla, "he servido a estos

${ }^{41}$ AGI, Justicia 870, n. 7. Carta poder de John Hawkins a Cristóbal de Santisteban. Monte Cristi a 7 de mayo de 1563, f. 87v.

${ }^{42}$ AGl, Justicia 999, n. 2, r. 2. Confesión de Cristóbal de Santisteban. Madrid a 3 de diciembre de 1565, f. 2 v. 
señores en registrar en la urca y carabela que de aquí [Monte Cristi] [espacio en blanco] el señor almirante dará relación muchos cueros y alguna azúcar y esto en mi nombre...". ${ }^{43}$ A decir del propio Cristóbal, este aceptó involucrarse con el inglés porque, de no hacerlo, colocaba en riesgo los intereses comerciales de su hermano, Pedro de Santisteban. A ello hay que agregar que, con el registro, la Corona no perdería sus derechos fiscales,

tenía este declarante en la dicha urca muchas mercaderías del dicho su hermano por no perderlas y en ello sirvió a Su Majestad porque mediante la claridad que hubo con el registro que este declarante hizo se tomó para Su Majestad y se excusó que los dichos ingleses no se lo llevasen a sus tierras... ${ }^{44}$

Así, Cristóbal de Santisteban aseguró que su participación en los tratos y contratos realizados en el marco de la presencia inglesa no fuera un delito; es más, sostuvo que Hawkins no era un corsario,

que no le tuvo este declarante por tal corsario ni hizo obras de tal, porque si lo fuera no sirviera a Su Majestad con 106 negros ni enviara su almirante a Sevilla como lo envió ni dejara de llevar muchos navíos que estaban surtos con él en los dichos puertos los cuales pudiera llevar con facilidad... ${ }^{45}$

Otro argumento esgrimido por De Santisteban fue que, gracias a que aceptó participar con el capitán inglés, este se abstuvo de emprender cualquier acto bélico contra los puertos que visitó y sus vecinos respectivos. De este modo lo declaró:

hizo gran servicio a Su Majestad y provecho y utilidad a toda la tierra y naturales de ella porque con hacer lo que hizo el dicho Cristóbal de Santisteban se aseguró la tierra y los navíos que estaban

${ }^{43}$ AGI, Justicia 870, n. 7. Carta de Cristóbal de Santisteban. Monte Cristi a 10 de junio de 1563, f. 32r.-v.

${ }^{44}$ AGI, Justicia 999, n. 2, r. 2. Confesión de Cristóbal de Santisteban. Madrid a 3 de diciembre de 1565, f. 2 r.

${ }^{45}$ Ibíd., f. 3r.-v. 
surtos en el dicho puerto [Monte Cristi] y las mercaderías que estaban en los dichos navíos... ${ }^{46}$

En este caso, De Santisteban solo fue un eslabón más dentro de la cadena de involucrados en los intercambios comerciales Ilevados a cabo en este primer viaje de Hawkins. El siguiente nodo de la red del capitán inglés fue un hombre llamado Utitón, cuyo nexo con la empresa de aquel fue a través del almirante de la flota, Tomás Antonio, además de que el padre Utitón era vecino de Plymouth, Inglaterra, de donde era Hawkins. Pero el vínculo más estrecho se sostuvo en que Utitón conocía también a Cristóbal de Santisteban, el cual le escribió una misiva respecto a la carga enviada de Monte Cristi a Sevilla. ${ }^{47}$ Según Utitón, toda la carga, tanto de la urca como de la carabela, estaba registrada y no había algo fuera de lugar o sin registro. En la carabela se hallaban 200 cueros y dos cajas de azúcares, mientras que en la urca, 160 cueros. De acuerdo con Pedro de Estrada, en total eran 386 cueros y una caja de azúcar. ${ }^{48}$ La participación de Utitón en esta red mercantil aún está por ser estudiada. Para los fines de este trabajo, basta con señalar su aparición en escena.

\section{Amenazas, pactos y comercio forzado durante la estancia de John Hawkins en el puerto de Río del Hacha (1565)}

El ejemplo que ahora exponemos ocurrió durante el segundo viaje de John Hawkins a las Indias occidentales, el cual se desarrolló entre octubre de 1564 y octubre de 1565, desde que zarpó de Inglaterra hasta su retorno. En 1565, el oidor de la Real Audiencia de Santo Domingo, el licenciado Diego Ortegón, fue el encargado

${ }^{46}$ Ibíd., f. 3v.

${ }^{47}$ AGl, Justicia 870, n. 7. Declaración de Utitón. Sevilla a 13 de septiembre de 1563, f. 30v.

${ }^{48}$ AGl, Justicia 870, n. 7. Declaración de Utitón. Sevilla a 13 de septiembre de 1563, f. 31 r.; AGI, Justicia 870, n. 7. Carta de Pedro de Estrada. Sevilla a 14 de septiembre de 1563, f. 33v.-34r. 
de reunir los testimonios sobre lo sucedido con la llegada del capitán Hawkins a Tierra Firme. En la cabeza de proceso encontramos lo siguiente,

a su noticia es venido que ciertos vecinos de la ciudad de La Vela y Río del Hacha habían rescatado con un navío inglés y otro portugués por el mes de abril próximo pasado de este presente año, en mucha cantidad de negros y otras muchas mercaderías... ${ }^{49}$

Alonso Pérez Roldán fue enviado por la Real Audiencia de Santo Domingo a dar aviso del cercano arribo de la armada inglesa. Luego de llevar la advertencia a Cabo de La Vela, Santa Marta, Cartagena de Indias y Nombre de Dios llegó a Río del Hacha donde los vecinos le informaron que pocos días atrás había estado el capitán Hawkins realizando la venta de esclavos negros. Así lo señaló Pérez Roldán: "el dicho inglés rescató con el tesorero de Su Majestad, que ahí está, [y] otros muchos vecinos...". ${ }^{50}$

¿Cómo se llevó a cabo el intercambio? El primer aspecto a señalar fue el arribo de la armada de Hawkins a Río del Hacha y el contacto inicial con los vecinos de aquel puerto. Esta parte de la historia del derrotero de esas naves inglesas comenzó un sábado cuando alrededor de las diez de la mañana el conjunto naval de Hawkins pudo ser vislumbrado, desde tierra, en el horizonte de Río del Hacha. Cuando las embarcaciones surgieron frente al puerto, "tiraron tres piezas de artillería con sus pelotas...", con el propósito de dar aviso de su llegada. Después el capitán inglés envío una embarcación con la cual algunos ingleses se adentraron al río. Ahí, según Diego Beltrán, tomaron preso a Baltasar Fuentes; pero también aquellos nautas estaban "sondando con una sonda las brazas que había de fondo...". La nave inglesa fue aproximándose a tierra y los hombres intentaron desembarcar, pero el tesorero Miguel de Castellanos, vecinos y demás habitantes no lo permitieron. Los ingleses en res-

${ }^{49} \mathrm{AGI}$, Patronato 195, r. 27. Cabeza de proceso. Santo Domingo a 18 de octubre de 1565 , f. 573 r.

${ }^{50}$ AGl, Patronato 195, r. 27. Declaración de Alonso Pérez Roldán. Santo Domingo a 18 de octubre de 1565 , f. 573 v.-574r. 
puesta advirtieron que venían "en paz y que no querían hacer daño ninguno a nadie...". Con estas palabras lograron su cometido: dar pie a las negociaciones para efectuar un intercambio comercial. A fin de redondear las muestras de amistad, los ingleses dejaron en libertad a Beltrán. ${ }^{51}$

Luego de ese primer contacto, los anglosajones procedieron a mencionar cuál era la razón que los Ilevó a aquel puerto. Según el cabildo de Río del Hacha, los ingleses solicitaron "que se les diese tierra para que con los vecinos pudiese vender los negros y otras mercaderías que traían para rescatar con ellos...". Este diálogo sucedió con el tesorero De Castellanos, quien estuvo "tratando entre los susodichos ingleses [...] las paces que querían rescatar de lo que traían...". La respuesta del cabildo a esa solicitud fue negativa, pues "no podían ni querían dar la dicha licencia, que se fuese con Dios del pueblo donde estaba surto...". Al respecto, Diego Beltrán declaró que "les respondieron que no querían rescatar con ellos cosa ninguna porque así les era mandado por la Audiencia Real de Santo Domingo y que se fuesen, a buena, a donde mejor les pareciese...". ${ }^{52}$ Este diálogo inicial no prosperó para la causa extranjera. Luego entonces, los anglosajones utilizaron otra forma.

Los ingleses emplearon la amenaza como un medio por el cual intimidar y acceder a la licencia para el intercambio comercial en Río del Hacha; esto implicaba, aparentemente, la antesala de un intercambio forzoso de mercancías. El capitán Hawkins mandó por segunda vez a algunos de sus hombres para pedir de nuevo "licencia para rescatar como la pedía, donde no que les había de hacer todo el más daño que pudiese...". Otro testimonio apuntó que los anglosajones respondieron "que rescatasen con ellos de voluntad sino que ello les harían que rescatasen de por fuerza...". Ante esta amenaza, la parte española solo contestó que "se hiciesen lo que

${ }^{51}$ AGI, Patronato 195, r. 27. Declaración de Diego Beltrán. Río del Hacha a 31 de julio de 1565, f. 582v.-583r.

${ }^{52}$ AGl, Patronato 195, r. 27. Probanza del cabildo de Río del Hacha. Río del Hacha a 23 de agosto de 1566, f. 729v.; AGI, Patronato 195, r. 27. Declaración de Diego Beltrán. Río del Hacha a 31 de julio de 1565, f. 583v. 
quisiesen que ellos harían lo que pudiesen...". O, en otras palabras, el cabildo sostuvo su postura, "que se fuesen con Dios y que no le querían dar la dicha licencia para el dicho rescate...". Una advertencia fue enviada por Hawkins a los hispanos de Río del Hacha,

pues no querían hacer lo que les habían pedido tantas veces que otro día, por la mañana, les daría el almuerzo desde sus navíos pues la noche antes le habían dado a él [Hawkins] mala cena por no querer hacer su voluntad y les había de quemar el pueblo, mantenimientos y matar los que pudiese... ${ }^{53}$

Lo que siguió superó la amenaza verbal, pues los ingleses pasaron a demostrar su capacidad ofensiva haciendo uso de las armas de que disponían. Así, el domingo, cinco bateles descendieron a cerca de 200 ingleses:

toda la gente armada con sus coseletes y morriones saltaron juntos al pueblo, todos en tierra, y uno de los navíos tiraban muchas pelotas a la gente que estaba en tierra. $Y$ antes que saltasen en tierra el dicho capitán Miguel de Castellanos con su gente que eran todos ellos hasta 60 hombres todos y entre ellos había negros e indios con sus armas [...] y visto la gente que había en defensa de ellos [los ingleses] empezaron a tirar de los barcos sus arcabuces y tiros que traían y de los navíos muchas pelotas, que los ojearon de donde estaban... ${ }^{54}$

Estas acciones de los anglosajones tuvieron resultado favorable a sus intereses, pues los españoles, según Diego Beltrán, decidieron no defender sino entablar las negociaciones para el intercambio comercial.

El argumento hispano al respecto fue el miedo a un mayor perjuicio que recibirían de no aceptar la exigencia de Hawkins,

${ }^{53}$ AGl, Patronato 195, r. 27. Declaración de Diego Beltrán. Río del Hacha a 31 de julio de 1565, f. 583v.; AGl, Patronato 195, r. 27. Probanza del cabildo de Río del Hacha. Río del Hacha a 23 de agosto de 1566, f. 730r.

${ }^{54}$ AGl, Patronato 195, r. 27. Declaración de Diego Beltrán. Río del Hacha a 31 de julio de 1565 , f. 585 r. 
y visto el daño que se podía sobre ellos recibir a los vecinos de esta ciudad de las muertes y robos que se ha acordado con el dicho tesorero capitán como persona más principal que se hiciese el susodicho rescate y así cesó por entonces el tirar de las pelotas y arcabuces que tiraban de los dichos bateles... ${ }^{55}$

Miguel de Castellanos refirió en su declaración que:

apremiado este testigo de las voces y parecer de todos los vecinos que presentes se hallaron en que decían que se diese licencia de que se rescatase con el dicho inglés que más justo era esto que no ver quemadas sus casas y haciendas y morirse por los campos que hijos y mujeres donde al presente estaban huyendo de los dichos ingleses por el temor de la muerte... ${ }^{56}$

Como es posible leer, las armas jugaron un papel relevante para conformar un acuerdo forzoso de intercambio comercial según una versión hispana. La supuesta negativa hispana fue quebrantada con la demostración del poder bélico de la armada anglosajona. Cristóbal Suárez de Ribas, vecino de aquella villa, apuntó que el intercambio comercial fue realizado bajo amenaza por parte de los ingleses: "que esto lo rescató por fuerza y daño que los dichos ingleses querían hacer a todos los vecinos en les querer quemar las casas y mantenimientos y otras muchas cosas que en ellas tenían...". Suárez de Ribas recalcó que el trato con los anglosajones no fue ocasión propicia para adquirir negros y demás productos a bajo costo, "y no por el provecho que de ellos se les seguía que por el costo que costaron...". Al finalizar su declaración, Suárez de Ribas insistió en señalar la existencia de una amenaza, por parte de los anglosajones, para explicar por qué sucedió el acuerdo de intercambio, "que lo hacen por la fuerza que el dicho inglés les hacía a todos y temores que les ponía en les decir que si no rescataban como ellos querían

${ }^{55}$ Ibíd.

${ }^{56}$ AGl, Patronato 195, r. 27. Declaración de Miguel de Castellanos. Río del Hacha a 7 de agosto de 1565, f. $658 \mathrm{v}$. 
que habían de quemar...". ${ }^{57}$ Otro vecino de Río del Hacha manifestó similar argumento: "y esto que lo hizo por la grande fuerza que el dicho inglés les hizo como se puede averiguar...". ${ }^{58}$ El tesorero Miguel de Castellanos aseguró, sobre este punto, que "si rescataron fue por la gran pujanza de gente y armas y artillería que los dichos ingleses traían y porque en este pueblo a la sazón no se hallaron más de obra de 40 y 50 españoles para en defensa del pueblo...". ${ }^{59}$ Un vecino más, Francisco de Lerma, dio el mismo testimonio: "los rescató por la fuerza que los dichos ingleses hicieron en el pueblo como se puede todo ello averiguar..." ${ }^{60}$

Según lo anterior, en efecto, hubo un acuerdo generalizado entre los vecinos de Río del Hacha para llevar a cabo el intercambio con John Hawkins, "y que el rescate se había hecho de voluntad de todos los vecinos del Río del Hacha...". No obstante, Pérez Roldán aseguró que todo lo hasta ahora descrito fue una puesta en escena con el fin de generar un argumento factible que justificase el intercambio comercial y, por tanto, evitar o disminuir las penas judiciales derivadas del trato y contrato con Hawkins. Así, a decir de Pérez Roldán, los vecinos de Río del Hacha lograron ponerse de acuerdo para proponer al capitán que fingiese amenazar a la villa con una incursión armada, "que dijese que quería asolar el pueblo y que hiciese con soltar algunos tiros por alto...". Los vecinos explicarían que el rescate realizado fue bajo amenaza, "diciendo que lo habían hecho por temor de aquello...". El propio Pérez Roldán destacó actitudes sospechosas del tesorero Miguel de Castellanos, el cual tuvo conversaciones privadas con Hawkins, "y era muy público entre

${ }^{57}$ AGI, Patronato 195, r. 27. Declaración de Cristóbal Suárez de Ribas. Río del Hacha a 3 de agosto de 1565, f. 645v.-646r.

${ }^{58}$ AGl, Patronato 195, r. 27. Declaración de Domingo Feliz. Río del Hacha a 4 de agosto de 1565 , f. 654 r.

${ }^{59} \mathrm{AGl}$, Patronato 195, r. 27. Declaración de Miguel de Castellanos. Río del Hacha a 7 de agosto de 1565, f. 658r.

${ }^{60} \mathrm{AGl}$, Patronato 195, r. 27. Declaración de Francisco de Lerma. Río del Hacha a 7 de agosto de 1565 , f. $659 \mathrm{v}$. 
los vecinos que el dicho tesorero hablaba a solas en partes en secreto con el capitán de los ingleses...". ${ }^{61}$

A pesar de las versiones contrapuestas, fue un hecho que después de la aceptación, forzada o no, del cabildo y del capitán general Miguel de Castellanos, para los tratos y contratos con Hawkins, se inició un procedimiento de recíproca seguridad. Una parte fundamental en las negociaciones fue establecer un marco de seguridad mutua para ambas partes, luego de haberse preparado para observar la capacidad de las fuerzas del respectivo oponente. Un acuerdo relevante para reforzar el pacto de no agresión fue la entrega de rehenes. En este caso, Diego Beltrán señaló que se dieron rehenes de una parte a otra y de otra a otra para tener entre ellos más seguridad y así se tomó el concierto entre ellos en que rescatasen todos los vecinos como lo pidió el susodicho inglés...". Mientras duró el intercambio comercial los ingleses estuvieron, al parecer, permanentemente en el puerto. Sobre ello, Pérez Roldán mencionó que "era muy público y notorio que los dichos ingleses estuvieron dos o tres días y noches varados en tierra los bateles y que si quisieran quemárselos lo pudieran hacer y no lo hicieron por hacer como hicieron el dicho rescate de su voluntad...". ${ }^{62}$

Una vez establecido lo anterior, siguieron las negociaciones de compra y venta generalizada. El fiscal enviado por la Corona para averiguar sobre la presencia de Hawkins en Río del Hacha fue el doctor Velasco, quien indicó que el modo concreto a través del cual unos y otros pusieron en marcha el acuerdo comercial, es decir la compra y venta, fue el trueque, pero también incluyó el pago con pesos de oro; la redacción de la pregunta hecha a los involucrados era de la siguiente forma, "este testigo compró de ellos ciertos negros y otras muchas ropas y mercaderías a trueque de oro, plata y

${ }^{61}$ AGl, Patronato 195, r. 27. Testimonio de Alonso Pérez Roldán. Santo Domingo a 18 de octubre de 1565, f. 574 r.

${ }^{62}$ AGl, Patronato 195, r. 27. Declaración de Alonso Pérez Roldán. Santo Domingo a 18 de octubre de 1565, f. 574v.; AGı, Patronato 195, r. 27. Declaración de Diego Beltrán. Río del Hacha a 31 de julio de 1565, f. 585r. 
perlas...". ${ }^{63}$ En ese sentido, y en este caso, podemos apuntar que el medio de pago empleado por los españoles puede ser catalogado no como moneda sino como un producto más, como un objeto más, el cual era posible usar para adquirir otros. De hecho, la palabra trueque provino del término trueco, que se definió así: "entrega que se hace de una cosa, tomando por ella otra equivalente, transfiriéndose el dominio mutuamente" (Real Academia Española, 1739, p. 370, 1-2). Pero, como ya indicamos, también se realizó el pago con pesos de oro, el cual estuvo circunscrito a la adquisición de negros esclavos.

Por otro lado, desde la opinión de Pérez Roldán, es posible apuntar un panorama sobre los productos que se intercambiaron durante el tiempo que perduró la compra: "doscientos negros a precio de ciento diez pesos cada uno, pagados con oro y en perlas y en plata y en joyas de oro...", además de otras mercancías. ${ }^{64}$ Iniciemos con las personas que adquirieron mercaderías para luego seguir con aquellos que lograron comprar o trocar negros por pesos de oro u otras piezas de intercambio. Uno de los productos ofertados por los ingleses fue el vino. Cristóbal Suárez de Ribas obtuvo "un pipón de vino que rescató para él y para Francisco Andrés [...] y el pipón de vino rescató en 60 pesos de oro...". Por su parte, Manuel González "rescató un pipón de vino para él y otras tres personas...". Asimismo, Hernando Costilla adquirió "un pipón de vino en 60 pesos y que lo rescató para tres o cuatro personas...." ${ }^{65}$ En efecto, cada pipón de vino mantuvo su precio durante su venta. Al igual podemos observar que el vino no estaba destinado para solamente una persona sino que fue compartido, aunque no sabemos cómo ni cuándo luego de la compra.

${ }^{63} \mathrm{AGl}$, Patronato 195, r. 27. Declaración de Rodrigo Caro. Río del Hacha a 2 de agosto de 1565, f. 641r.

${ }^{64}$ AGI, Patronato 195, r. 27. Declaración de Alonso Pérez Roldán. Santo Domingo a 18 de octubre de 1565, f. 574 r.

${ }^{65}$ AGl, Patronato 195, r. 27. Declaración de Cristóbal Suárez de Ribas. Río del Hacha a 3 de agosto de 1565, f. 645v.; AGI, Patronato 195, r. 27. Declaración de Manuel González. Río del Hacha a 3 de agosto de 1565, f. 648v.; AGı, Patronato 195, r. 27. Declaración de Hernando Costilla. Río del Hacha a 4 de agosto de 1565, f. 645v. 
Telas de diferente tipo fueron parte de las mercancías puestas en venta por los anglosajones. Rodrigo Sánchez logró "una vara de paño azul del cual hizo un paledo que le costó cuatro pesos de oro y medio...". Francisco Ribero, alguacil mayor, "rescató 26 varas de ruán a cinco o cuatro reales cada una vara...". El tesorero De Castellanos consiguió "ocho varas de telilla de oro y lo rescató para la iglesia de esta dicha ciudad y allí está en la dicha iglesia y que de lo que sobró de ello se hizo una saya a una niña hija suya...". A este personaje cabe agregar que "por ser el precio tan bueno y que asimismo había rescatado mercaderías de lienzos, harinas, habas, bizcochos, vinos...". Al parecer, Lázaro de Vallejo compró ropa que los ingleses le ofrecieron. Estos también ofertaron un par de pipas con habas, las cuales pasaron a manos de Francisco Ribero, luego de entregar diez pesos de oro, "para comer él y su gente de mujer e hijos y que les costaron 10 pesos cada una pipa...". Incluso hubo equipamiento para el campo de lo ecuestre. Rodrigo Caro compró "unas espuelas de rodete las cuales le costaron medio peso...". ${ }^{66}$

A diferencia de los productos recién enlistados, los esclavos negros fueron la principal mercancía ofertada por los ingleses. A decir de algunos testimonios, tal parece que la gran mayoría de los vecinos de Río del Hacha estuvieron involucrados en la compra de hombres y mujeres de color extraídos de Guinea. Varios habitantes apuntaron que la compra de los esclavos fue realizada en forma generalizada por los vecinos de la villa. El vicario, Antón Verdugo, subrayó que "otros vecinos compraron negros...". Por su parte, Rodrigo Caro, vecino, señaló que "otros muchos compraron negros de los dichos ingleses...". El también vecino Manuel González dijo que "otros muchos vecinos rescataron negros pero que no sabe

${ }^{66}$ AGl, Patronato 195, r. 27. Declaración de Rodrigo Sánchez. Río del Hacha a 2 de agosto de 1565, f. 640r.; AGı, Patronato 195, r. 27. Lázaro de Vallejo. Río del Hacha a 4 de agosto de 1565, f. 650v.; AGI, Patronato 195, r. 27. Declaración de Francisco Ribero. Río del Hacha a 4 de agosto de 1565, f. 651v.; AGl, Patronato 195, r. 27. Declaración de Miguel de Castellanos. Río del Hacha a 7 de agosto de 1565, f. 656r.; AGl, Patronato 195, r. 27. Declaración de Alonso Pérez Roldán. Santo Domingo a 18 de octubre de 1565, f. 574r.; AGl, Patronato 195, r. 27. Declaración de Rodrigo Caro. Río del Hacha a 2 de agosto de 1565 , f. $641 \mathrm{v}$. 
los negros que rescataron ni cuantos fueron...". Francisco Ribero, alguacil mayor, declaró que "otros muchas personas rescataron negros y negras del dicho inglés...". ${ }^{67}$

Consignamos los nombres de algunos vecinos y estantes que adquirieron a aquellos hombres y mujeres procedentes de África. Es de resaltar la participación de diversos miembros de la sociedad de Río del Hacha. En primer lugar subrayamos la existencia de dos grupos: uno compuesto por algunos miembros del cabildo y familiares de estos, además de unos cuantos vecinos; el otro aglutinó básicamente a vecinos y estantes en aquel puerto. Los miembros del primer grupo fueron Miguel de Castellanos, tesorero pero además capitán general de la compañía española que intentó hacer frente a la armada de Hawkins; Baltasar de Castellanos, hermano de Miguel; Rodrigo Caro, Hernando Costilla y Francisco de Lerma, todos ellos vecinos. En cuanto al segundo grupo encontramos a los siguientes vecinos: Alvar Sánchez de Vega, Diego Beltrán, Rodrigo Sánchez, Cristóbal Suárez de Ribas, Manuel González, Lázaro de Vallejo, Domingo Feliz, Gaspar Días, Alonso Pérez de Tolosa, el hijo, Cristóbal de Villacastín, Rodrigo Sánchez, Catalina de Villayzan, Pedro de Urribarri, Héctor Tejeda y Jaime Rafael. Acompañaban a todos ellos el alguacil mayor Francisco Ribero; Antón Verdugo, vicario presbítero; y Diego Guerrero, quien era un fiador de Pedro Mejía, vecino de Cartagena de Indias, quien también participó de aquella compra.

Ahora bien, es posible arrojar cierta luz, al menos en términos generales, en cuanto a los acuerdos entre vendedores y compradores a partir de los costos de cada una de las piezas de esclavos negros. Por una parte observamos que los vecinos de Río del Hacha necesitaron entre 45 y hasta 260 pesos de oro. Cristóbal Suárez de Ribas apuntó que "vio rescatar negros con el dicho inglés y negras

${ }^{67}$ AGl, Patronato 195, r. 27. Declaración de Antón Verdugo. Río del Hacha a 2 de agosto de 1565, f. 643r.; AGI, Patronato 195, r. 27. Declaración de Rodrigo Caro. Río del Hacha a 2 de agosto de 1565, f. 641v.; AGI, Patronato 195, r. 27. Declaración de Manuel González. Río del Hacha a 3 de agosto de 1565, f. 648r.; AGI, Patronato 195, r. 27. Declaración de Francisco Ribero. Río del Hacha a 4 de agosto de 1565, f. 651v. 
a 160 y 180 pesos en oro fino..."; $;$ precios que se encontraban en el rango ya indicado. Dentro de este margen es posible hallar espacio, metafóricamente hablando, para distintas explicaciones sobre la colocación de los costos. Por un lado advertimos que los hombres de color con un valor situado entre 45 y 80 pesos de oro no estaban físicamente adecuados o tenían alguna característica que no había sido consignada en el expediente. Por ejemplo, Alvar Sánchez de Vega señaló que dos de los negros que compró a 50 pesos de oro llegaron a ese precio porque estaban enfermos, de hecho, poco tiempo después fallecieron. ${ }^{69}$ Hernando Costilla mencionó que de la docena de piezas que adquirió, algunos a 80 pesos de oro, era porque estaban cojos y enfermos; otros los obtuvo en 50 pesos de oro, aunque no explicó el porqué de ese precio. ${ }^{70}$ Francisco Ribero indicó que una de las mujeres de color que adquirió fluctuaba entre los 45 y 55 pesos de oro, pero tampoco apuntó la razón de ese costo. ${ }^{71}$

El precio más constante fue de 135 pesos de oro. Probablemente esa cantidad era el monto a pagar por esclavos en condiciones adecuadas. Quienes compraron en este precio no señalaron algún dato que ayude a entender en qué se sostuvo tal costo. Lo que resulta mucho más claro es que el volumen de compra, nos inclinamos a plantear, no afectó el valor de los negros a menos que, suponemos, haya habido algún tipo de negociación entre ingleses y españoles. ¿Acaso eran varios ingleses los encargados de vender y, por tanto, diferentes los precios, o la calidad de los hombres y mujeres de color influyó en el precio con el que fueron marcados? Esta misma pregunta puede aplicarse al caso de Miguel de Castellanos, quien a pesar de adquirir 25 negros, 19 o 20 de ellos costaron 95 pesos de oro, mientras que los restantes, 175 pesos de oro; o al de Alvar

${ }^{68} \mathrm{AGl}$, Patronato 195, r. 27. Declaración de Cristóbal Suárez de Ribas. Río del Hacha a 3 de agosto de 1565, f. 646r.

${ }^{69}$ AGl, Patronato 195, r. 27. Declaración de Alvar Sánchez de Vega. Río del Hacha a 2 de agosto de 1565, f. 644r.

${ }^{70} \mathrm{AGl}$, Patronato 195, r. 27. Declaración de Hernando Costilla. Río del Hacha a 4 de agosto de 1565 , f. 649 r.

${ }^{71}$ AGl, Patronato 195, r. 27. Declaración de Francisco Ribero. Río del Hacha a 4 de agosto de 1565 , f. $651 \mathrm{v}$. 
Sánchez de Vega, quien por dos personas de color desembolsó 260 pesos de oro. No tenemos información sobre ello.

Pero además de los posibles convenios en precios entre ingleses y españoles, es factible registrar otros acuerdos para la reventa de los hombres y mujeres de color sucedidos entre los propios españoles de Río del Hacha. Por ejemplo, el tesorero Miguel de Castellanos aseguró que del lote de esclavos y esclavas vendió tres a Cristóbal Suárez de Ribas, misma cantidad a Diego Guerrero, una negra a Héctor Tejeda y otra más a Pedro de Urribarri. De Castellanos afirmó que "se las dio porque se lo rogaron así que les rescatase estas piezas entre las suyas que le rescató...". Esto puede venir a aclarar aún más el panorama sobre las negociaciones de compra y venta entre extranjeros e hispanos, pues Tejeda y Urribarri no habrían negociado con los ingleses sino con De Castellanos. En efecto, ese par de personajes señalaron que del tesorero adquirieron la única pieza de esclavos proveniente de los ingleses. Mientras que Suárez de Ribas y Guerrero probablemente hayan obtenido tanto de los anglosajones como del tesorero piezas de gente de color, pues en las declaraciones recabadas por el fiscal de Su Majestad, Suárez de Ribas y Guerrero indicaron solo haber adquirido dos piezas de esclavos. Miguel de Castellanos, asimismo, subrayó que "se las dio a su riesgo porque de ellos no ganó cosa ninguna más de se le dar por el propio precio como rescataba las suyas y porque ellos todos se lo rogaron y están así a su riesgo...". ${ }^{72}$ Según estos dichos, parece que no hubo ganancia para el tesorero, pero no contamos con más datos para sostener tales declaraciones. A pesar de ello, es posible aseverar que, en cierto momento, De Castellanos fungió como una especie de intermediario entre los ingleses y aquel par de españoles.

${ }^{72}$ AGI, Patronato 195, r. 27. Declaración de Miguel de Castellanos. Río del Hacha a 7 de agosto de 1565, f. 656r.; AGl, Patronato 195, r. 27 . Declaración de Pedro de Urribarri. Río del Hacha a 7 de agosto de 1565, f. 663r.; AGl, Patronato 195, r. 27 . Declaración de Héctor Tejeda. Río del Hacha a 7 de agosto de 1565, f. 662r. 
El contador Hernando Costilla fue un vecino que vendió piezas de negros a por lo menos otros dos habitantes de Río del Hacha. Así lo indicó: "y que los dichos negros los rescató para él y para otras personas de este pueblo que son para Diego Beltrán y para doña Catalina de Villayzan y no para otras personas...". Tal parece que hubo un acuerdo previo entre las partes. A decir de la declaración de Costilla, a este le solicitaron que fuese para adquirir, además de sus piezas de esclavos, al menos otras cinco. Beltrán solicitó tres, mientras que doña Catalina solo dos. Al respecto de esta última, Costilla apuntó lo siguiente: a ella "le rescató una pieza porque le dijo que le rescatase dos y se las rescató con las suyas y después no quiso tomar más que una pieza porque dijo que no tenía dinero...". Sobre esto, doña Catalina declaró que "es verdad que el dicho contador Hernando de Costilla le dio a esta declarante una negra de las que el dicho contador rescató y la tiene hoy día en su poder y casa...". Además de este ejemplo podemos mencionar a Lázaro de Vallejo, quien vendió a Jaime Rafael, en 160 pesos de oro, una de las negras compradas a los ingleses. Pedro Mejía dio su par de esclavos, obtenidos en la venta inglesa, en fianza a Diego Guerrero para que este las Ilevase a Cartagena de Indias. Cristóbal de Villacastín dejó en custodia una de las mujeres de color que adquirió de los anglosajones a Rodrigo Caro para que este la entregase a un hombre Ilamado Fulano de Río Verde. ${ }^{73}$

Pero también hubo vecinos que no formaron parte del acuerdo comercial con el capitán Hawkins. Esto colocaba a quienes participaron en ello en riesgo de ser denunciados y, por ende, de sufrir algún tipo de castigo. Así lo expresó Pérez Roldán, "muchos vecinos a este testigo y a otros, los que no habían gozado del rescate, que si

${ }^{73} \mathrm{AGl}$, Patronato 195, r. 27. Declaración de Hernando Costilla. Río del Hacha a 4 de agosto de 1565, f. 649r.-v.; AGI, Patronato 195, r. 27. Declaración de Lázaro de Vallejo. Santo Domingo a 4 de agosto de 1565, f. 650v.; AGI, Patronato 195, r. 27. Declaración de Diego Guerrero. Río del Hacha a 13 de agosto de 1565, f. 670r.-v.; AGl, Patronato 195, r. 27. Declaración de Catalina de Villayzan. Río del Hacha a 7 de agosto de 1565, f. 666r.; AGl, Patronato 195, r. 27. Declaración de Cristóbal de Villacastín. Río del Hacha a 13 de agosto de 1565 , f. 672 v.-673r. 
iba juez a averiguar lo susodicho que le habían de decir la manera y trato que tuvieron con el dicho inglés para hacer el susodicho rescate...". ${ }^{74}$ A decir de Pedro de la Peña, un estante en Río del Hacha, "no rescató de los navíos de los ingleses cosa ninguna de negros ni de mercaderías de lo que los susodichos ingleses traían...". Otros de los vecinos que no comerciaron con los ingleses fueron Baltasar de Castellanos, Diego Guerrero y Alonso Pérez de Tolosa, el mozo. ${ }^{75}$ Pero a pesar de que la totalidad de los vecinos del puerto de Río del Hacha no estuvo involucrada directamente en la compra y venta de mercancías y esclavos, podemos observar un panorama que sugiere que las manufacturas y productos adquiridos fueron distribuidos en múltiples ámbitos de la vida cotidiana en aquel lugar.

\section{Consideraciones finales}

Según lo expuesto, es factible distinguir un esquema básico para llevar a buen puerto los intercambios comerciales entre corsarios y la sociedad colonial de litoral. En primera instancia, las negociaciones se daban con los capitanes corsarios y las autoridades hispanas. El fin era obtener la anuencia de los representantes de la Corona. Unos y otros buscaban entablar el diálogo para llegar a un acuerdo comercial. Las pláticas podían venir después de hostilidades, amenazas de algunas de las partes involucradas o desde marcos iniciales de no hostilidad. Las licencias para comerciar representaban el medio por el cual los corsarios podían tratar y contratar con ciertas medidas de seguridad, pero también implicaban estar de pie en el campo de lo legal, de lo autorizado por los funcionarios del rey en

${ }^{74}$ AGI, Patronato 195, r. 27. Declaración de Alonso Pérez Roldán. Santo Domingo a 18 de octubre de 1565 , f. 574v.

${ }^{75}$ AGl, Patronato 195, r. 27. Declaración de Pedro de la Peña. Río del Hacha a 7 de agosto de 1565, f. 665r.; AGI, Patronato 195, r. 27. Declaración de Baltasar de Castellanos. Río del Hacha a 7 de agosto de 1565, f. 667r.; AGI, Patronato 195, r. 27. Declaración de Alonso Pérez de Tolosa, el mozo. Río del Hacha a 13 de agosto de 1565, f. 669v.; AGI, Patronato 195, r. 27. Declaración de Diego Guerrero. Río del Hacha a 13 de agosto de 1565, f. 670r.-v. 
Indias. De otorgar la licencia, ambas partes pactaban un marco de seguridad mutua o de no agresión inclusive intercambiando rehenes entre extranjeros e hispanos. Una vez sucedido esto, procedían al desembarco de las mercancías y esclavos para su venta o intercambio. Aquí las posibilidades de negociaciones entre unos y otros fueron amplias. La venta de las mercancías y esclavos formó parte de la segunda fase en los intercambios comerciales; era en sí la entrada y primera distribución de las mercancías a la sociedad que las adquiría. Existieron asimismo otras distribuciones, dependiendo de las redes sociales de quien obtenía por primera vez las manufacturas y gente de color ofertada por los corsarios. En este sentido podemos hablar del encuentro de súbditos de diferentes Coronas en el Nuevo Mundo y, con ello, la conformación de relaciones sociales particulares, en este caso en el Golfo-Caribe durante el siglo XVı. Hay que agregar las maneras en las cuales no se respetaban los acuerdos, por ejemplo, engaños, traiciones y emboscadas. Todo esto también coadyuvó a dar forma a la sociedad americana de la época colonial. En conjunto podemos hablar de una sociedad de litoral, destacando su flexibilidad en cuanto a recibir, convivir y establecer diversas negociaciones con corsarios anglosajones y galos.

De hecho, los acuerdos comerciales que Ilegaron a concretarse o no, integraron la vida en el Golfo-Caribe, fueron parte de las posibilidades que el espacio marítimo ofreció en cuanto a que dotó de recursos, no solo naturales, sino además, por medio de los tratos y contratos con los hombres del mar, la gente que estuviese en tierra podía acceder a mercancías que dentro del marco de los tratos y contratos de la Carrera de Indias podrían resultar inviables adquirir. En pocas palabras, el mar también arrojaba posibilidades de satisfacer necesidades de abastecimiento por medio del comercio con los corsarios. Esto queda en claro, según los ejemplos, porque desde las más altas autoridades de los respectivos puertos hasta los vecinos y estantes estuvieron involucrados en los tratos y contratos con ingleses y franceses durante el siglo XVI. Pero no todos tuvieron igual participación. Tal parece que aquellos que estuvieron 
estrechamente cercanos a los corsarios o quienes encabezaron, por la parte hispana, las negociaciones tuvieron mayor participación en la actividad mercantil, ya sea acaparando mercancías y esclavos o fungiendo como intermediarios, inclusive obteniendo algún beneficio económico derivado de los tratos y contratos. La temática es un campo fértil para la investigación.

\section{Fuentes citadas}

\section{ARCHIVO}

Archivo General de Indias (AGI)

\section{REFERENCIAS}

Andrade Muñoz, G. L. (2006). Un mar de intereses. La producción de pertrechos navales en Nueva España, siglo XVIII. México: Instituto Mora.

Azcárraga y de Bustamante, J. L. (1950). El corso marítimo (concepto, justificación e historia). Madrid: Consejo Superior de Investigaciones Científicas/Instituto Francisco de Vitoria.

Bernand, C., y Gruzinski, S. (2005). Historia del Nuevo Mundo. Tomo II: Los mestizajes. México: Fondo de Cultura Económica.

Blanes, M. (2001). Fortificaciones del Caribe. Madrid: Letras Cubanas.

Bordejé Morencos, F. (1992). Tráfico de Indias y política oceánica. Madrid: Mapfre.

Caballero Juárez, J. A. (1997). El régimen jurídico de las armadas de la Carrera de Indias, siglos XVI y XVII. México: Instituto de Investigaciones Jurídicas-Universidad Nacional Autónoma de México.

Casanova Rosado, A. A., Rocher Salas, A. D. y Ordóñez Contreras M.R. (1995). Campeche intramuros. Campeche, México: Universidad Autónoma de Campeche.

Cruz Barney, O. (1997). El régimen jurídico del corso marítimo: el mundo indiano y el México del siglo XIX. México: Instituto de Investigaciones Jurídicas-Universidad Nacional Autónoma de México. 
Cruz Barney, O. (2009). El corso marítimo. Influencias de la Ordonnance de la Marine de 1681 en el derecho hispanoindiano. México: Instituto de Investigaciones Jurídicas-Universidad Nacional Autónoma de México.

De la O, R. (2013). Testimonios de la defensa. Españoles contra corsarios en Yucatán, 1559-1608. En P. Peniche Moreno (Coord.), Con el pasado en la mira. Estudios historiográficos (pp. 135-172). Mérida, Yucatán: Cepsa Editorial.

De la O, R. (2014). De corsarios, mares y costas. El corso en la construcción del espacio Golfo-Caribe. 1527-1620 (Tesis de doctorado). Centro de Investigaciones y Estudios Superiores en Antropología Social-Peninsular, Mérida, Yucatán.

Delgado Ribas, J. (2007). Dinámicas imperiales (1650-1796). España, América y Europa en el cambio institucional del sistema colonial español. Barcelona: Edicions Bellaterra.

Elliot, J. H. (2006). Imperios del mundo atlántico. España y Gran Bretaña en América, 1492-1830 (M. Blacells, Trad.). Madrid: Taurus-Historia.

Franco, J. L. (2008). Historia de la revolución de Haití. Santo Domingo, República Dominicana: Sociedad Dominicana de Bibliófilos.

Gall, F. y Gall, J. (2014). El filibusterismo (2a ed.). México: Fondo de Cultura Económica.

García de León, A. (2004). Contra viento y marea. Los piratas en el Golfo de México. México: Plaza y Janés.

García de León, A. (2014). Vientos bucaneros. Piratas, corsarios y filibusteros en el Golfo de México. México: Biblioteca Era.

García Martínez, B. (2009). Prólogo. Reflexiones sobre el tiempo y la distancia. En J. Long Towell y M. Attolini Lecón (Coords.), Caminos y mercados de México (pp. 19-23). México: Universidad Nacional Autónoma de México/Instituto Nacional de Antropología e Historia.

García Venegas, I. (1997). Impactos de la piratería en Campeche durante el siglo XVII (Tesis de licenciatura). Facultad de Filosofía y Letras-Universidad Nacional Autónoma de México, México.

García Venegas, I. (2003). Los ladrones de los mares y San Francisco de Campeche. En R. Piña Chán (Dir.), Enciclopedia histórica de Campeche, Tomo II. Época colonial (pp. 555-640). México: Porrúa/Gobierno del Estado de Campeche. 
Georget, H., y Rivero, E. (1994). Herejes en el paraíso. Corsarios y navegantes ingleses en las costas de Venezuela durante la segunda mitad del siglo XVI. Caracas: Arte.

Gonzalbo Aizpuru, P. (2009). Vivir en Nueva España. Orden y desorden en la vida cotidiana. México: El Colegio de México.

Grafenstein Gareis, J. von (1997). Nueva España en el Circuncaribe, 17791808. Revolución, competencia imperial y vínculos intercoloniales. México: Universidad Nacional Autónoma de México.

Grafenstein Gareis, J. von (2006). El Golfo-Caribe y sus puertos. Tomo I, 1600-1850. México: Instituto Mora.

Grafenstein Gareis, J. von Muñoz, L. y Nelken, A. (2006). Un mar de encuentros y confrontaciones. El Golfo-Caribe en la historia nacional. México: Secretaría de Relaciones Exteriores.

Hakluyt, R. (1904 [1586]). The principal navigations, voyages, traffiques and discoveries of the English Nation (vol. 10). Glasgow, Reino Unido: James MacLhose.

Haring, C. (1984). Comercio y navegación entre España y las Indias en la época de los Habsburgos (E. Salinas, Trad.). México: Fondo de Cultura Económica.

Hoffman, P. E. (1980). The Spanish Crown and the Defense of the Caribbean, 1535-1585. Precedent, Patrimonialism, and Royal Parsimony. Luisiana: Louisiana State University Press.

Ita Rubio, L. de (2001). Viajeros isabelinos en la Nueva España. México: Fondo de Cultura Económica.

Jarmy Chapa, M. de (1987). La expansión española hacia América y el océano Pacífico. Tomo I. Un eslabón perdido en la historia: piratería en el Caribe, siglos XVI y XVII (2a ed.). México: Distribuciones Fontamara.

Kennedy, P. (2007). Auge y caída de las grandes potencias (F. Aleu, Trad.). México: Debolsillo.

Klein, H. S., y Vinson, B., III (2013). Historia mínima de la esclavitud en América Latina y el Caribe. México: El Colegio de México.

López Zea, L. (2003). Piratas del Caribe y Mar del Sur en el siglo XVI (14971603). México: Universidad Nacional Autónoma de México.

Lucena Salmoral, M. (1992). Piratas, bucaneros, filibusteros y corsarios en América. Perros, mendigos y otros malditos del mar. Madrid: Mapfre.

88 • Revista MeXICANA del CARIBE 21 / 2016 (pp. 42-89) 
Moreau, J.-P. (2012). Piratas, filibusteros y piratería en el Caribe y en los Mares del Sur (1522-1725). Madrid: Antonio Machado Libros. Muñoz Espejo, F. M. (2005). La construcción de la fortaleza de San Juan de Ulúa. México.

Pérez Turrado, G. (1992). Las armadas españolas de Indias. Madrid: Mapfre. Quezada, S., y Okoshi Harada, T. (2001). Papeles de los Xiu de Yaxá, Yucatán. México: Instituto de Investigaciones Filológicas-Universidad Nacional Autónoma de México.

Real Academia Española (1737). Diccionario de la lengua castellana, en que se explica el verdadero sentido de las voces, su naturaleza y calidad, con las phrases o modos de hablar, los proverbios o refranes, y otras cosas convenientes al uso de la lengua [...]. Compuesto por la Real Academia Española. Tomo quinto. Que contiene las letras O.P.Q.R. Madrid: Imprenta de la Real Academia Española, por los herederos de Francisco del Hierro.

Real Academia Española (1739). Diccionario de la lengua castellana, en que se explica el verdadero sentido de las voces, su naturaleza y calidad, con las phrases o modos de hablar, los proverbios o refranes, y otras cosas convenientes al uso de la lengua [...]. Compuesto por la Real Academia Española. Tomo sexto. Que contiene las letras S.T.V.X.Y.Z. Madrid: Imprenta de la Real Academia Española, por los herederos de Francisco del Hierro.

Serna, J. M. (2000). Esclavos, mulatos y negros: su papel en las estrategias territoriales y la diplomacia abolicionista en el Circuncaribe. En J. von Grafenstein y L. Muñoz (Coords.), El Caribe: región, frontera y relaciones internacionales. Tomo I (pp. 63-86). México: Instituto Mora.

Solow, B. (1991). Slavery and the Rise of the Atlantic System (B. Solow, Ed.). Cambridge, Reino Unido: Cambridge University Press.

Victoria Ojeda, J. (2000). El emplazamiento arquitectónico defensivo en el Campeche colonial. Campeche: Gobierno del Estado de Campeche/Instituto de Cultura de Campeche.

Wolf, E. (2006). Europa y la gente sin historia (A. Bárcenas y H. Pons, Trads.). México: Fondo de Cultura Económica. 